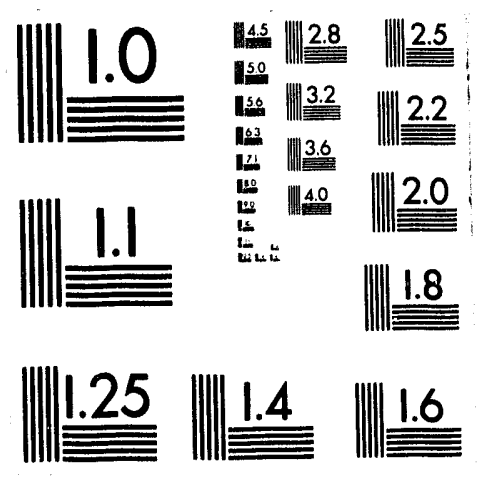



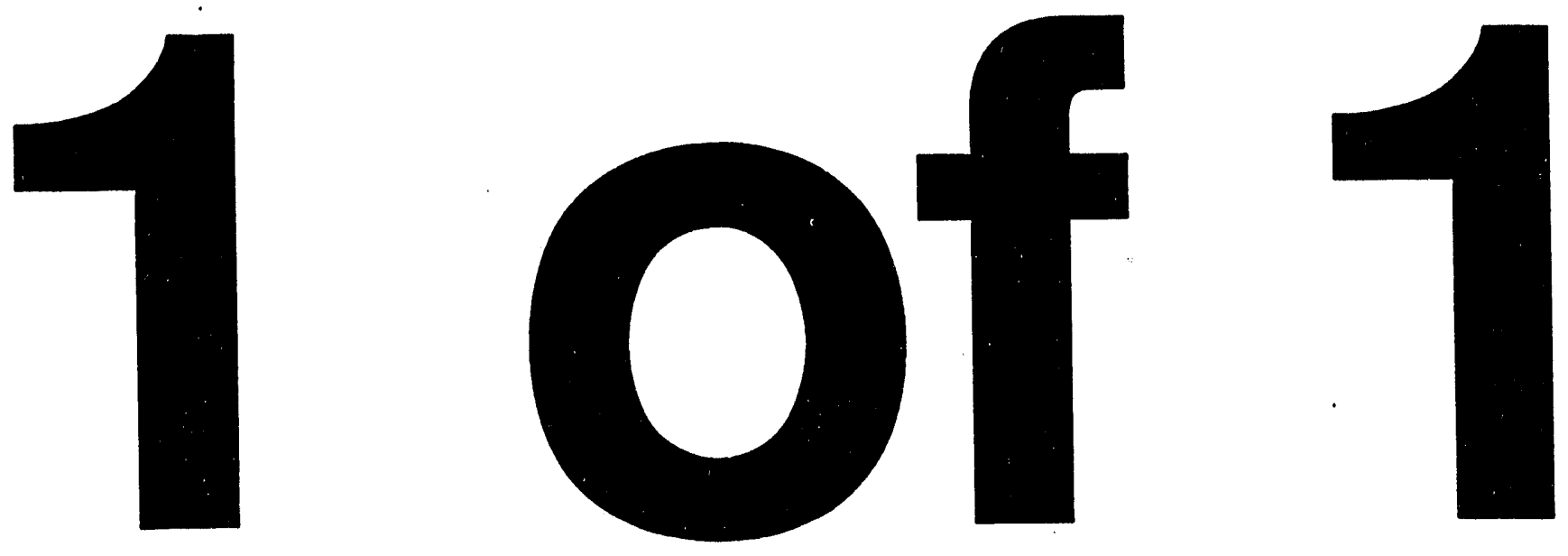
SAND93-0905

Unlimited Release

Printed October, 1993

Distribution

Category UC-

705

\title{
Two-Dimensional Quasistatic Modeling of Exclusion Region Barriers in Support of Design Guide Development
}

\author{
Gerald W. Wellman, Kathleen V. Diegert, and R. Salzbrenner \\ Engineering Mechanics and Material Modeling Department, \\ Statistics and Human Factors Department, and \\ Mechanical and Corrosion Metallurgy Department \\ Sandia National Laboratories \\ Albuquerque, New Mexico 87185
}

\begin{abstract}
Modern nuclear safety themes depend on excluding unwanted energy from the components required for nuclear detonation. The exclusion region barrier is designed to provide protection from extraneous energy. The barrier must remain unbreached for both normal operations and accident events. Recent advances in computational capabilities permits more accurate modeling of barrier tearing during the extreme mechanical loadings associated with accidents. This report describes a methodology which employs design of experiments strategies coupled with finite element analyses and testing to produce results suitable for inclusion in a guide to design exclusion region barriers.

The general approach was to employ finite element analyses to define the effect of materials property and geometric feature parameters on a generic barrier geometry. These parametric studies were based on design of experiments strategies. Four materials properties and six geometric features were included in the parameters. Selected geometries were tested to provide verification of the analyses. Statistical analysis of the results from the finite element analyses identified the important parameters (primarily the material property, true strain-tofailure, along with certain geometric characteristics) which were used to synthesize simplified equations and graphics suitable for inclusion into a guide for designers and safety analysts.
\end{abstract}




\section{Contents}

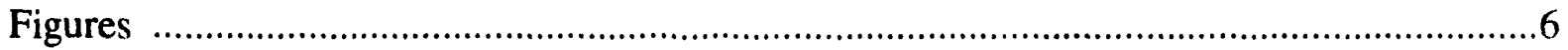

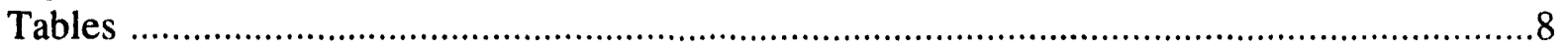

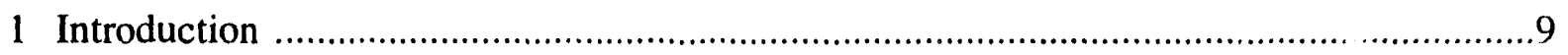

2 Exclusion Region Barrier Model ......................................................................11

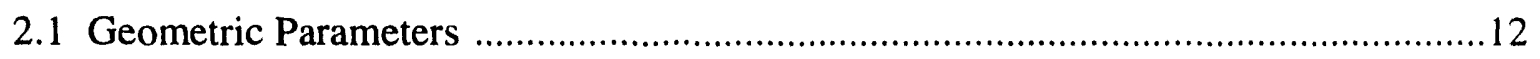

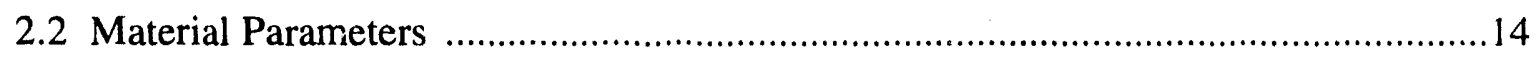

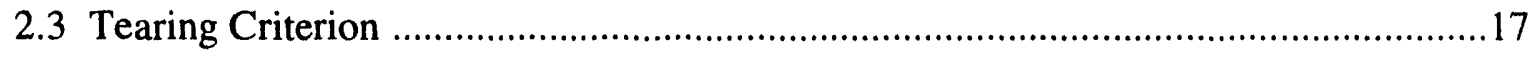

3 Finite Element Analysis Results .......................................................................21

3.1 Truncated Cone Geometry - Puncture Loading Environment .................................21

3.2 Truncated Cone Geometry - Crush Loading Environment ......................................22

3.3 Cylinder Geometry - Puncture Loading Environment ......................................22

3.4 Cylinder Geometry - Crush Loading Environment ..............................................23

3.5 Hemisphere Geometry - Puncture Loading Environment ....................................23

3.6 Hemisphere Geometry - Crush Loading Environment ........................................24

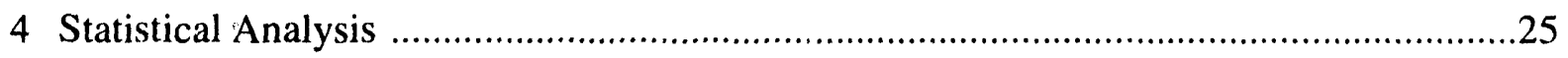

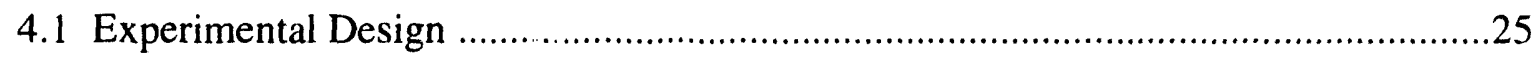

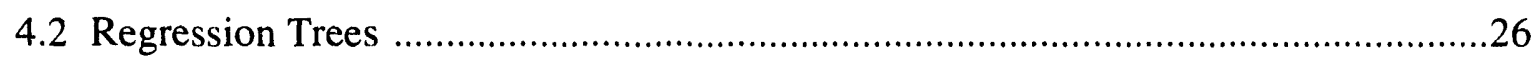

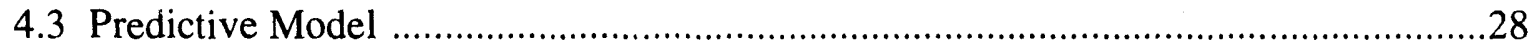

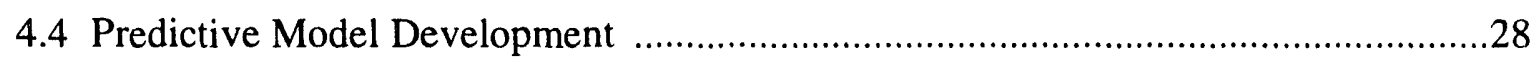

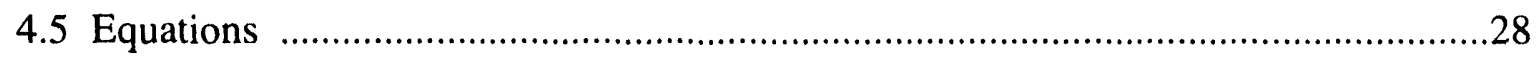

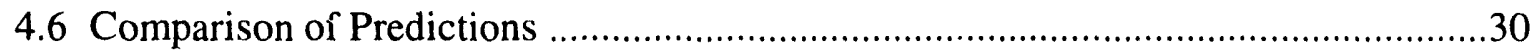

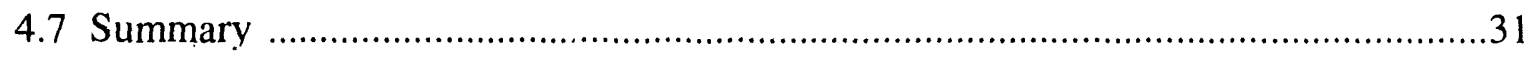

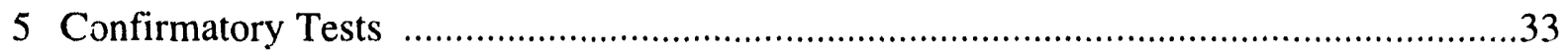

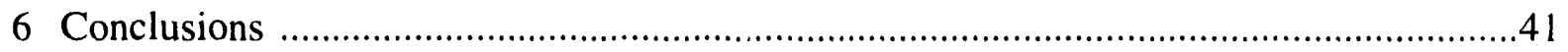

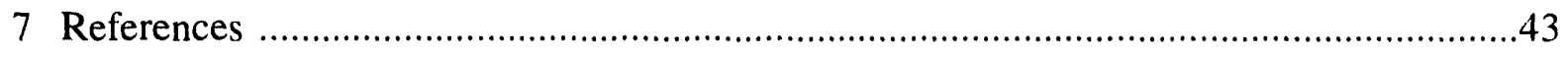

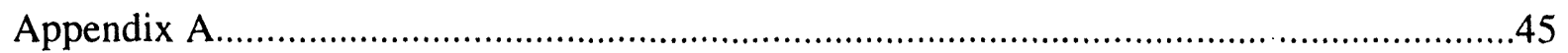

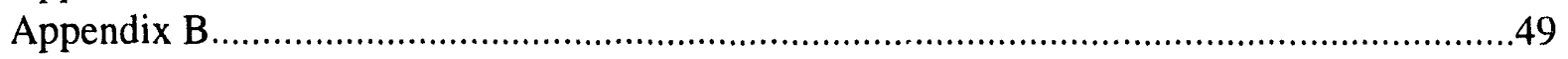

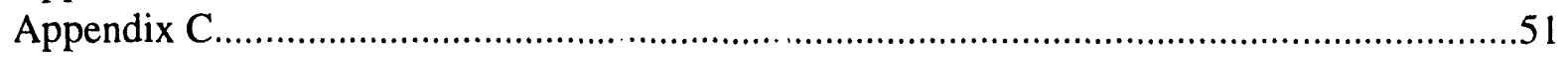




\section{Figures}

$1 \quad$ Fundamental Geometry of the Truncated Cone .............................................11

2 Geometric Parameters Selected to Generate a Conical Geometry ............................12

3 Geometric Parameters Selected to Generate a Hemispherical Geometry ...................13

4 Geometric Parameters Selected to Generate a Cylindrical Geometry .......................13

5 True-Stress Verses True-Strain Curves for the Material Parameters with a Low Yield Strength .................................................................................... 15

6 True-Stress Versus True-Strain Curves for the Material Parameters with an Inter-

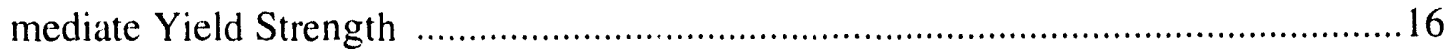

7 True-Stress Versus True-Strain Curves for the Material Parameters with a High

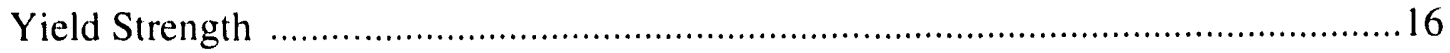

8 Contours of Plastic Strain and Tearing Parameter at Failure for a Tensile Test with a Yield Strength of $103 \mathrm{ksi}$, a Hardening Constant of $83 \mathrm{ksi}$, a Hardening Exponent of 0.26 , and a Strain-to-Failure of 1.27

9 Deformed Shape of the Truncated Cone Loaded by the Small Diameter Punch

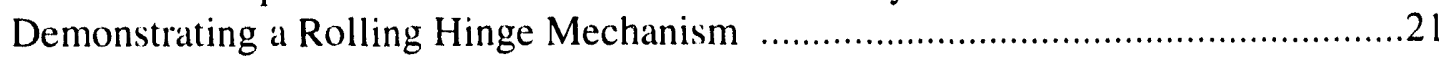

10 Deformed Shape of the Cylinder Loaded by the Small Diameter Punch Showing

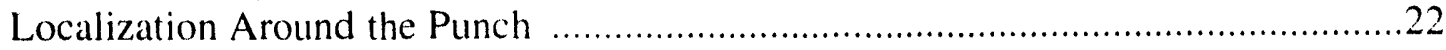

11 Deformed Shape of the Cylinder Loaded by the Large Diameter Punch Demonstrat-

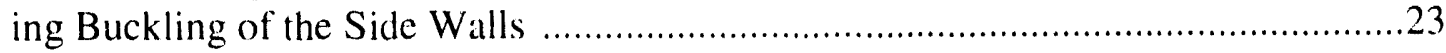

12 Regression Tree Diagram for the Puncture Environment ( $D=1$ inch) ...................27

13 Regression Tree Diagram for the Crush Environment ( $D=10$ inch) .....................27

14 Comparison Between the Predicted and Computed Displacement to Failure for the Puncture Environment

15 Comparison Between the Predicted and Computed Displacement to Failure for the

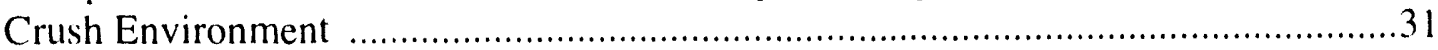

16 Load versus Displacement and Deformed Shapes for the 304 Cone ........................34

17 Load versus Displacement and Deformed Shapes for the 6061-T0 Cone .................35

18 Load versus Displacement and Deformed Shapes for the 6061-T6 Cone .................35

19 Load versus Displacement and Deformed Shapes for the 304 Cylinder ..................36

20 Load versus Displacement and Deformed Shapes for the 6061-T0 Cylinder ............36

21 Load versus Displacement and Deformed Shapes for the 6061-T6 Cylinder ............37

22 Load versus Displacement and Deformed Shapes for the 304 Hemisphere ...............37

23 Load versus Displacement and Deformed Shapes for the 6061-T0 Hemisphere ........38

24 Load versus Displacement and Deformed Shapes for the 6061-T6 Hemisphere ........38 


\section{Tables}

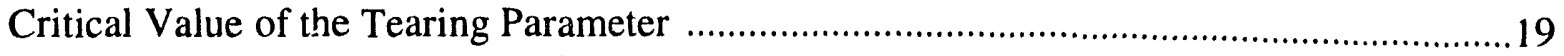

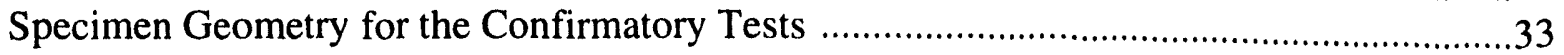

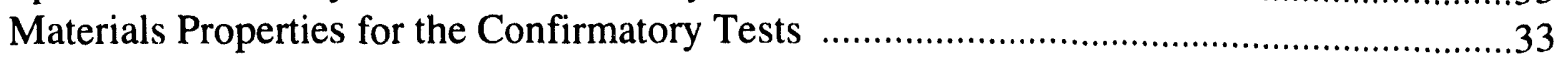

Matrix of the 97 Sets of Parameter Combinations ..........................................................45

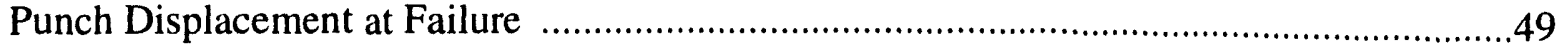

Predicted Displacement to Failure for the Puncture Environment .....................................51

Predicted Displacement to Failure for the Crush Environment ...........................................53 



\section{Introduction}

Modern nuclear safety themes depend on excluding unwanted energy or information from Region III (Region III components are required for nuclear detonation). These components provide both isolation and transmission of critical energies to the physics package. The exclusion region barrier encloses Region III and is designed to prevent unwanted energy from entering. To ensure nuclear safety, the barrier must remain continuous (i.e., no tearing) for both normal operations (stockpile-to-target) and during abnormal or accident events. Abnormal events include (among others), the application of high voltage, directional fires, crush loadings, penetration loadings, and combinations of these. The large scale deformation associated with crush and penetration are the least well characterized events and are the subject of this research program.

Historically, the exclusion barrier was combined with the fireset housing. Barrier materials were selected, among other criteria, on their ability to divert or insulate electrical energy, their producibility (castability, machinability, and weldability), and their strength. High strength was employed in order to gain a margin of safety for elastic design to withstand the mechanical loading associated with normal operations. The selection of barrier geometry was based on the Region III components to be surrounded and on the space available within the weapon. Abnormal event loading was typically addressed by testing.

The objective of the Advanced Barrier Mechanical Modeling Project is to develop and verify improved numerical modeling of the mechanical behavior of exclusion region barriers. This capability will allow quantification of the response of barriers to abnormal mechanical loadings. This project has the further objective of translating the improved modeling capabilities into easily applied guidance for designers and nuclear safety analysts. The ultimate goal is to develop a design guide that will aid engineers in making a more knowledgeable tradeoff among the competing aspects of barrier design such as tearing resistance, ease of fabrication, and resistance to normal environmental effects of shock and vibration.

In the initial phase of this project, the analytical tools were qualified against experimental results[1]. This report describes the initial work done in Phase 2 of the project, the development of quantitative guidelines for barrier design. The general approach taken was to perform parametric studies of the effects of materials property and geometric feature variations on a generic barrier geometry using design of experiments strategies. The generic barrier was represented by a shell structure formed into a truncated cone. The load was applied through downward motion of a punch located at the top of the cone. Four material property and six geometric parameters were varied in this initial evaluation. Finite element analyses of barriers defined by combinations of these ten parameters were carried out. The number of finite element analyses required and the combination of the parameters for each analysis was determined by using a central composite design of resolution IV [2]. This design consisted of a $2^{10-4}$ fractional factorial (64 runs), plus axial points for the four material parameters ( 8 runs), plus a center point ( 1 run) for a total of 73 finite element analyses in the matrix. This experimental design minimized the variance estimates of the parameter effects among experimental designs with the same number of runs. Based on these results [3], the original matrix was enhanced by an additional 24 analyses for a total of 97 . These additional 24 analyses were chosen to further define the influence of the parameters determined to be the 
most important from the initial portion of this study.

Only quasistatic mechanical loadings, associated with puncture and crush events, are considered in this study. Dynamic loadings, such as projectile penetration and high speed impact, are studied elsewhere [4]. The explicit, quasistatic finite element code JAC2D [5], was used to perform the analyses reported here.

Section 2 of this report describes the fundamental geometry and modeling assumptions of the generic barrier. It includes a description of how the fundamental geometry changes as the geometric parameters vary. The constitutive relation is explained and the effects of the materials parameters are discussed. Finally, the criterion used to determine the initiation of ductile tearing is described. Section 3 is devoted to presenting selected results from the finite element analyses. The statistical analysis of the finite element results is presented in Section 4. In Section 5, confirmatory experiments are compared to analyses. 


\section{Exclusion Region Barrier Model}

The basic structure chosen for this study is a simple truncated cone, shown in Figure 1. This basic shape allows the identification of parameters that will result in a wide variety of fundamentally different geometric behavior. The parameters and resulting geometries will be discussed in detail in the next section. The truncated cone also permits the use of twodimensional, axisymmetric analyses rather than three-dimensional analyses.

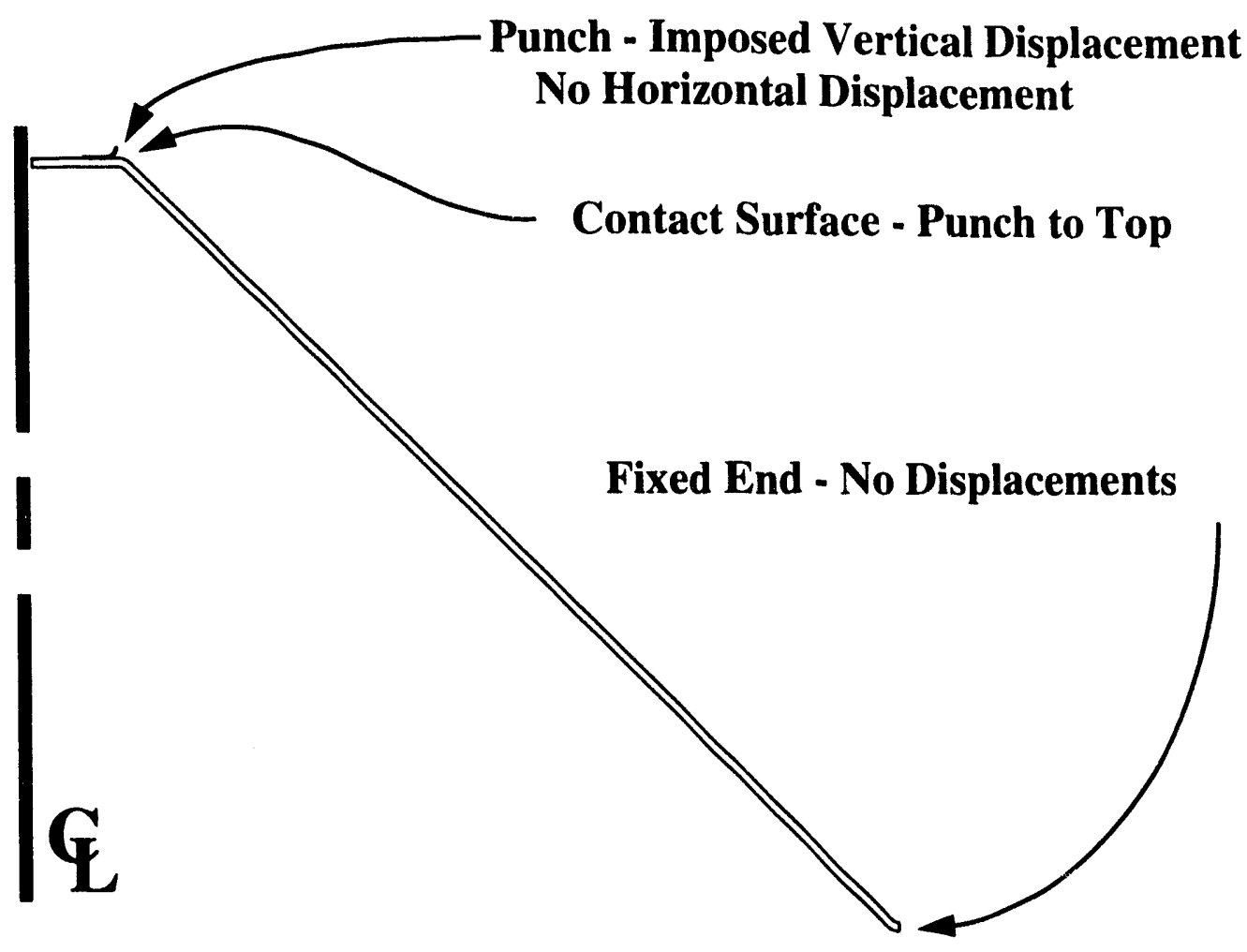

Figure 1. Fundamental Geometry of the Truncated Cone

The punch is located at the narrow, top of the cone. The punch is constrained from horizontal displacement and a vertical downward displacement boundary condition is applied. The bottom, large end of the cone is constrained to prevent both vertical and horizontal displacement. The use of a displacement controlled loading scheme provides a more stable solution, particularly when buckling or other phenomena resulting in unloading are encountered. Displacement control also implies an accident event in which infinite load is available to ensure the imposed displacement. No internal components are included in this model. In fact, displacement of the top or walls of the cone below the fixed bottom is allowed. The analysis was terminated on two conditions. By default, the solution was stopped when the punch had traveled 4.5 inches downward, the initial cone height. The punch displacement was also terminated when strain localization in the cone wall resulted in such severe element deformation that a numerical fault (element inversion, overflow, etc.) occurred in the finite element code. 


\subsection{Geometric Parameters}

The following six geometric parameters were evaluated: the top thickness $\left(t_{t}\right)$, the side thickness $\left(t_{s}\right)$, the top diameter (b), the punch diameter (D), the radius between the side wall and the bottom $\left(r_{s b}\right)$, and the radius between the side wall and the top $\left(r_{s t}\right)$. These parameters are shown in Figure 2.

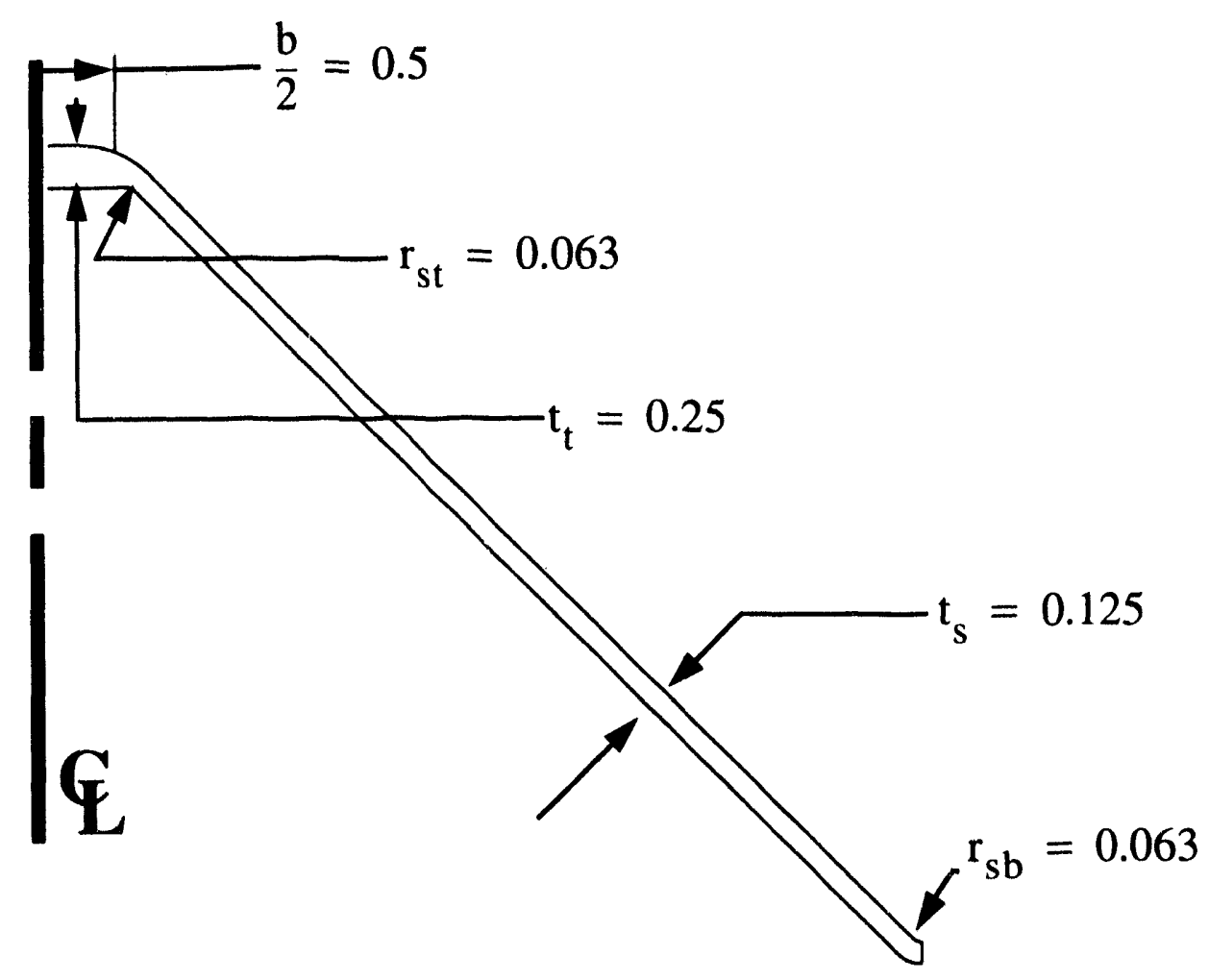

Figure 2. Geometric Parameters Selected to Generate a Conical Geometry

By changing the top diameter and the side-to-top radius, geometries approximating a hemisphere or a cylinder can be generated. A hemisphere is approximated with a small top diameter and a large side-to-top radius. A cylinder is obtained with a large top diameter and a small side-to-top radius. These geometries are shown in Figure 3 and Figure 4. 


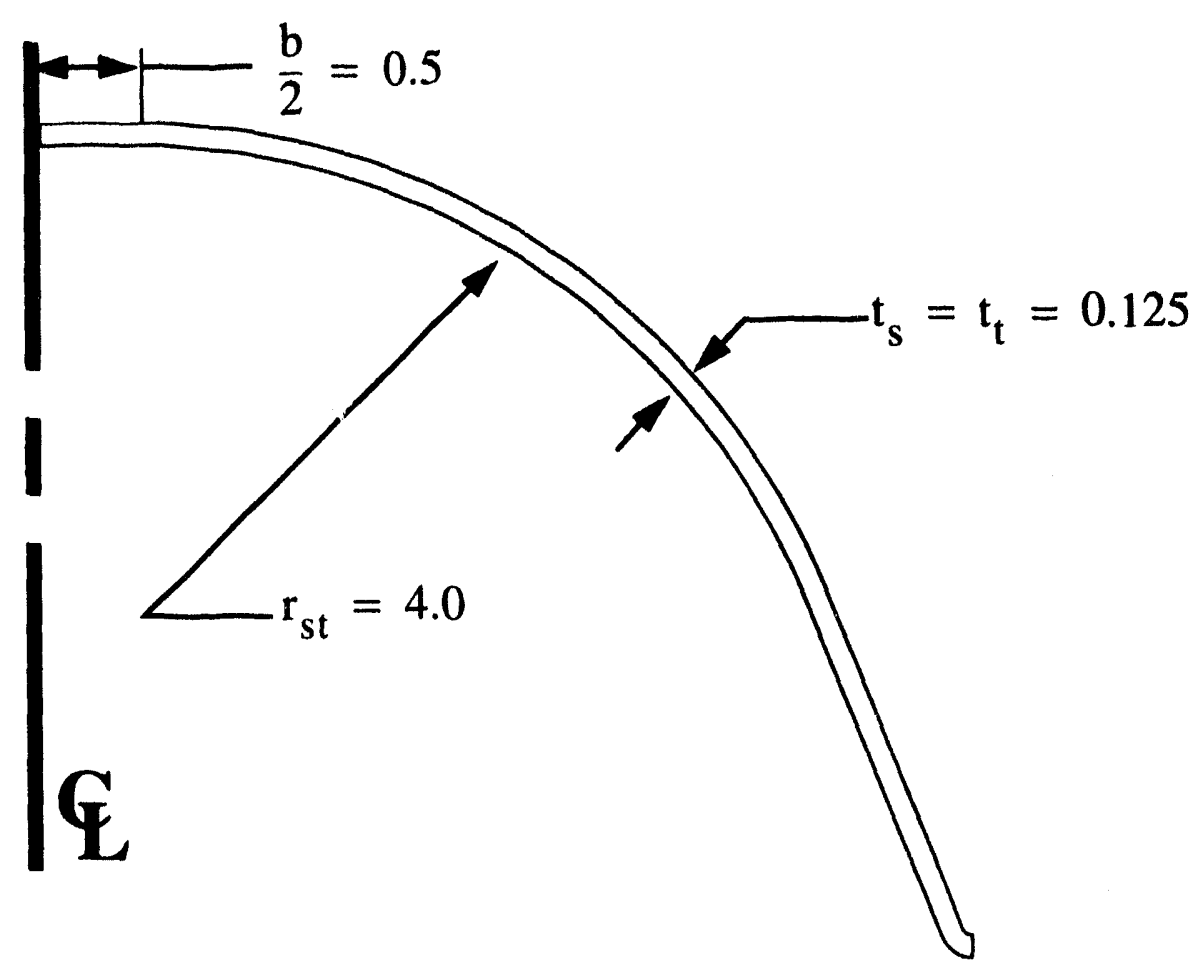

Figure 3. Geometric Parameters Selected to Generate a Hemispherical Geometry

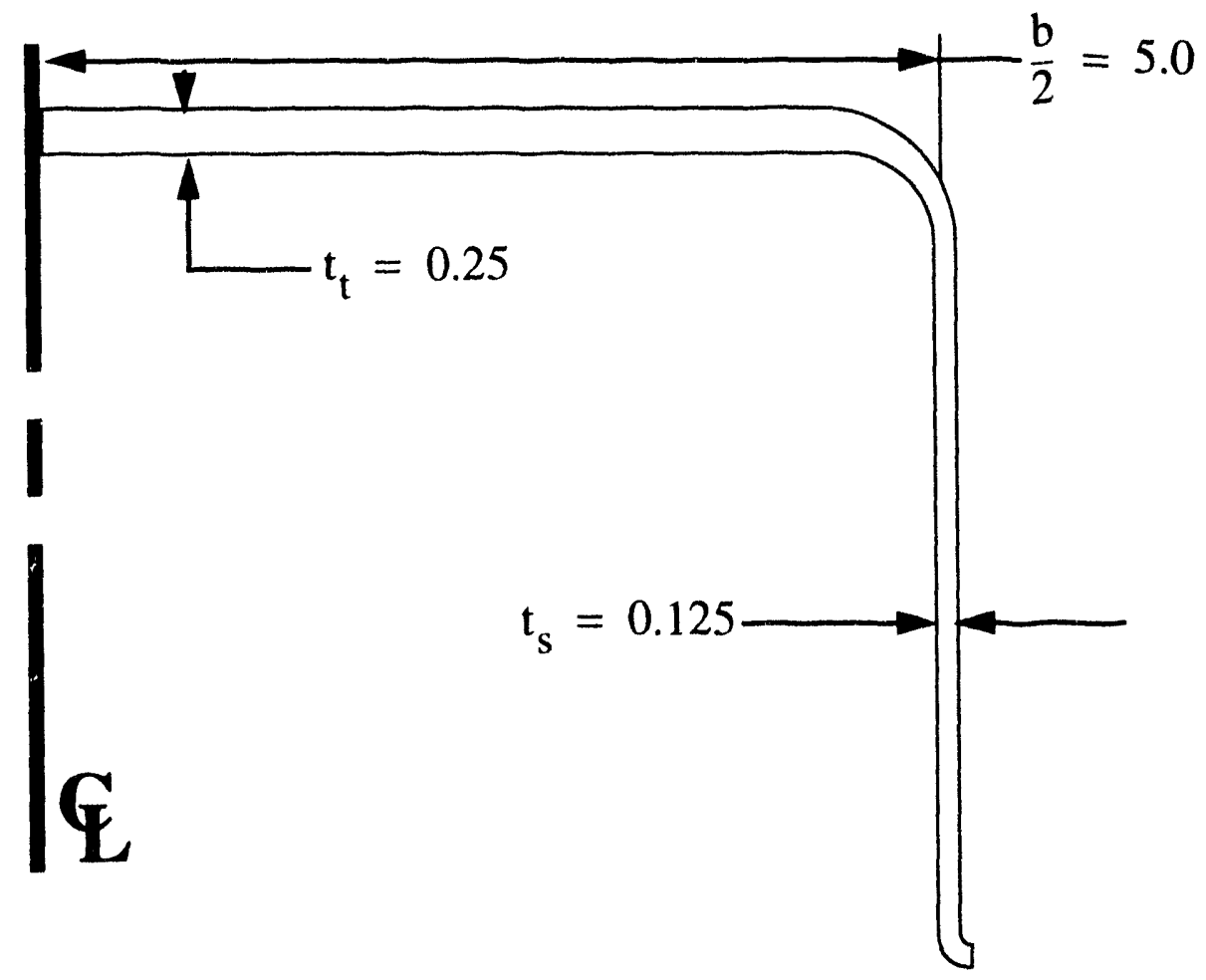

Figure 4. Geometric Parameters Selected to Generate a Cylindrical Geometry 
For this study, two values were chosen for each geometric parameter with an intermediate point included to determine the linearity of the effect of that parameter. The side thickness varied from 0.05 to 0.125 inch with an intermediate value of 0.088 inch. The top thickness was not permitted to be less than the side thickness because it was felt that this combination of parameters would lead to uninteresting very early localization and failure around the punch. For convenience, the top thickness was considered a dependent variable of the side thickness and the parameter top thickness minus side thickness $\left(t_{t}-t_{s}\right)$ was introduced. This parameter varied from 0 . to 0.2 inch with an intermediate value of 0.125 inch. These three values for top thickness minus side thickness resulted in four values of top thickness, 0.05, 0.125, 0.169, and $0.25 \mathrm{inch}$. The top diameter took a minimum value of $1.0 \mathrm{inch}$, a maximum value of 10.0 inches, and an intermediate value of 6.0 inches. The punch diameter took the same extreme values, 1.0 and 10.0 inches with an intermediate value of 5.0 inches. The side-to-bottom radius varied from 0.063 inch to 0.5 inch with an intermediate value of $0.25 \mathrm{inch}$. The side to top radius took on values of, $0.063,0.25$, and 0.5 inches. In addition, a 4.0 inch side-to-top radius was used with the 1 inch top diameter to approximate the geometry of a hemisphere.

\subsection{Material Parameters}

The materials are modeled using a constitutive relationship which has an initial linear elastic region followed by a strain hardening region characterized by a power law[6]:

$$
\bar{\sigma}=\sigma_{y s}+A\left\langle\bar{\varepsilon}_{p}-\varepsilon_{L}\right\rangle^{n}
$$

where:

$\sigma_{y s}$ is the initial yield stress,

$\mathrm{A}$ is the hardening constant,

$\mathrm{n}$ is the hardening exponent,

$\varepsilon_{p}$ is the equivalent plastic strain,

$\bar{\sigma}$ is the current value of the effective stress, and

$\varepsilon_{\mathrm{L}}$ is the Luiders strain or strain in the yield plateau.

A Luiders strain of zero was used throughout this study. Typically materials. with zero Luiders strain have no obvious yield point. For these materials, the proportional limit is more appropriate to use for the initial yield stress, $\sigma_{y s}$, than the more commonly tabulated $0.2 \%$ offset value. $\mathrm{A}$ and $\mathrm{n}$ are constants typically derived from a least squares fit to the stress-strain curve. In this study, $\sigma_{\mathrm{ys}}, \mathrm{A}$, and $\mathrm{n}$ were three of the constitutive parameters investigated. The fourth, $\varepsilon_{\mathrm{f}}$, will be discussed in detail later. $\sigma_{\mathrm{ys}}$ was varied from 20 to $120 \mathrm{ksi}$, A from 40 to $300 \mathrm{ksi}$, and $\mathrm{n}$ from 0.15 to 0.8 . The values of the constants were not chosen to represent any particular material, but the range in values encompasses most engineering alloys of practical interest in exclusion barrier fabrication. Values of these constitutive parameters for $304 \mathrm{~L}$ annealed stainless steel, and two heat treatments (T6 and T0) of 6761 aluminum alloy are 
given inTable 3, Section 5. While 6061 aluminum alloy is not typically used for structural purposes in the annealed, T0 heat treat condition, the other two materials (6061-T6 aluminum alloy and 304L stainless steel) are candidate materials for exclusion region barriers.

The stress-strain curves resulting from all combinations of parameters used in this study are shown in Figure 5, Figure 6, and Figure 7. The curves are labeled with the constitutive parameters that generated them in the order, $\sigma_{\mathrm{ys}}, \mathrm{A}$, and $\mathrm{n}$. For example, the curve labeled $37-$ 83-69 had a yield strength $\left(\sigma_{\mathrm{ys}}=37 \mathrm{ksi}\right)$, a hardening constant $(\mathrm{A}=83 \mathrm{ksi})$, and a hardening exponent $(n=0.69)$. In general, the hardening constant controls the magnitude of the strain hardening, while the hardening exponent controls the curvature of the stress-strain curve. A characteristic of the power law constitutive model is that the stress at a strain of 1.0 is equal to the yield strength plus the hardening constant. A low value of the hardening exponent indicates the material strain hardens rapidly at low strains and then increases more gradually. A high value of hardening exponent indicates a more gradual strain hardening $(n=1.0$ results in linear hardening).

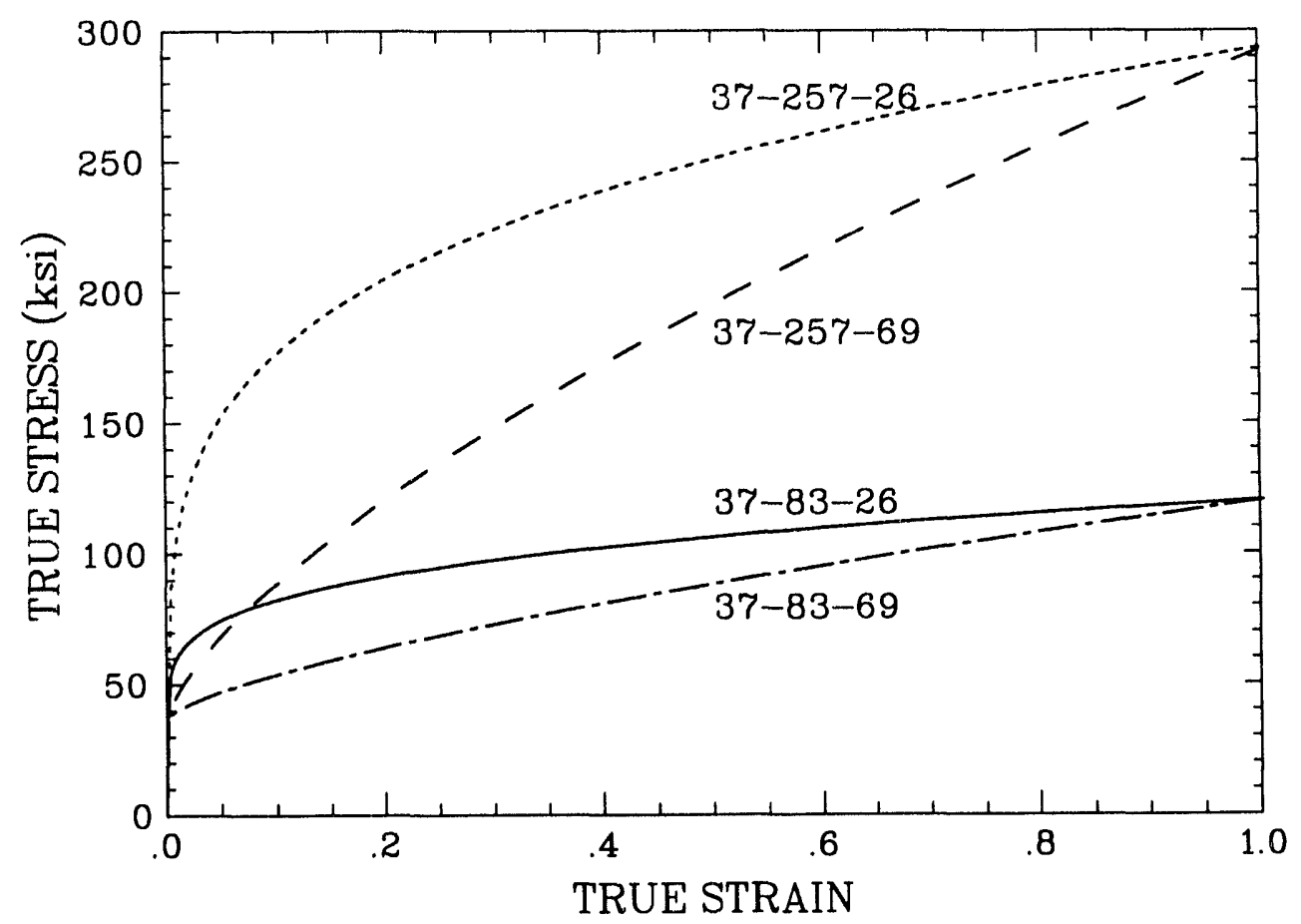

Figure 5. True-Stress Verses True-Strain Curves for the Material Parameters with a Low Yield Strength 


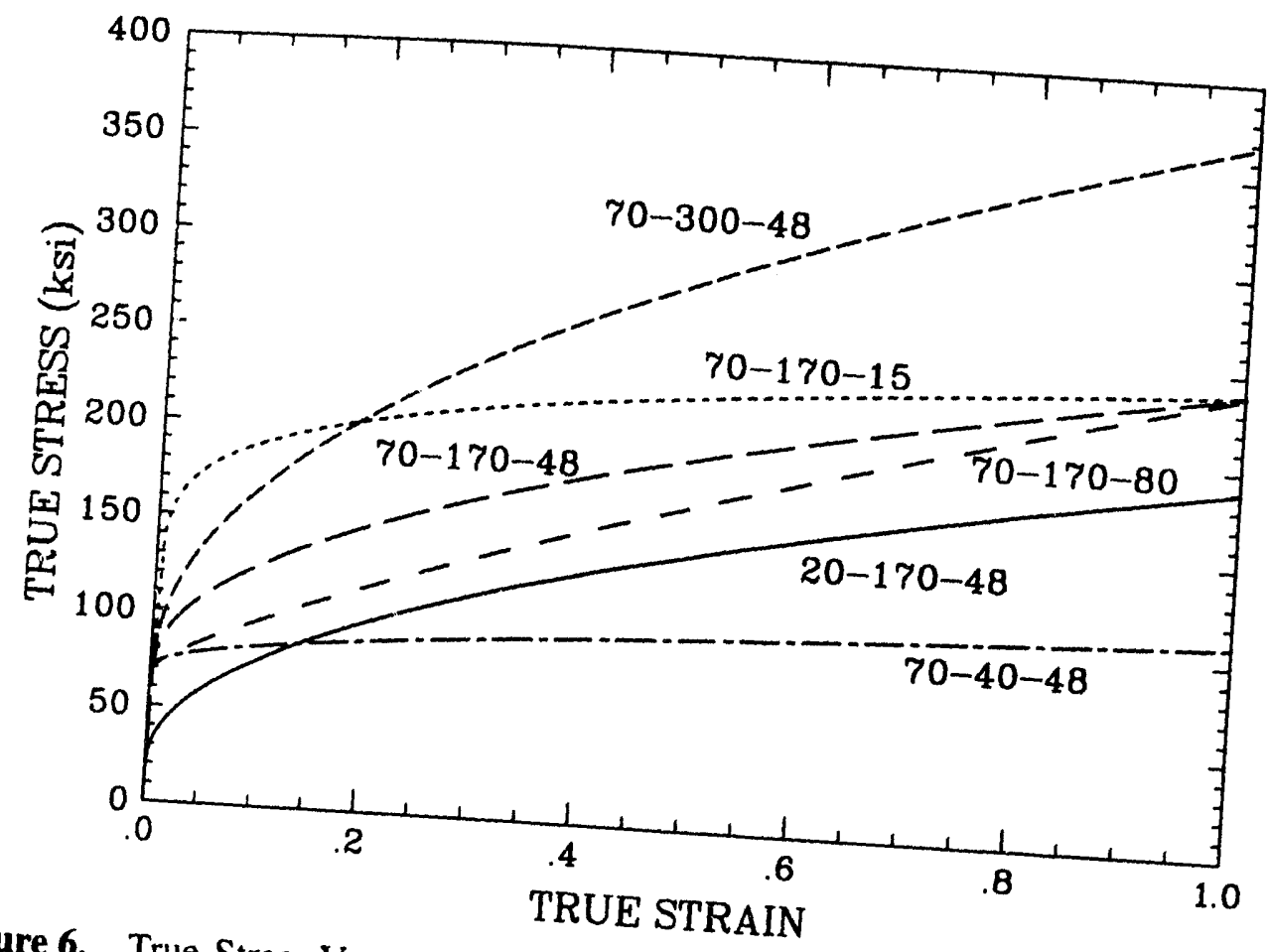

Figure 6. True-Stress Versu with an Intermediate Yield Strength

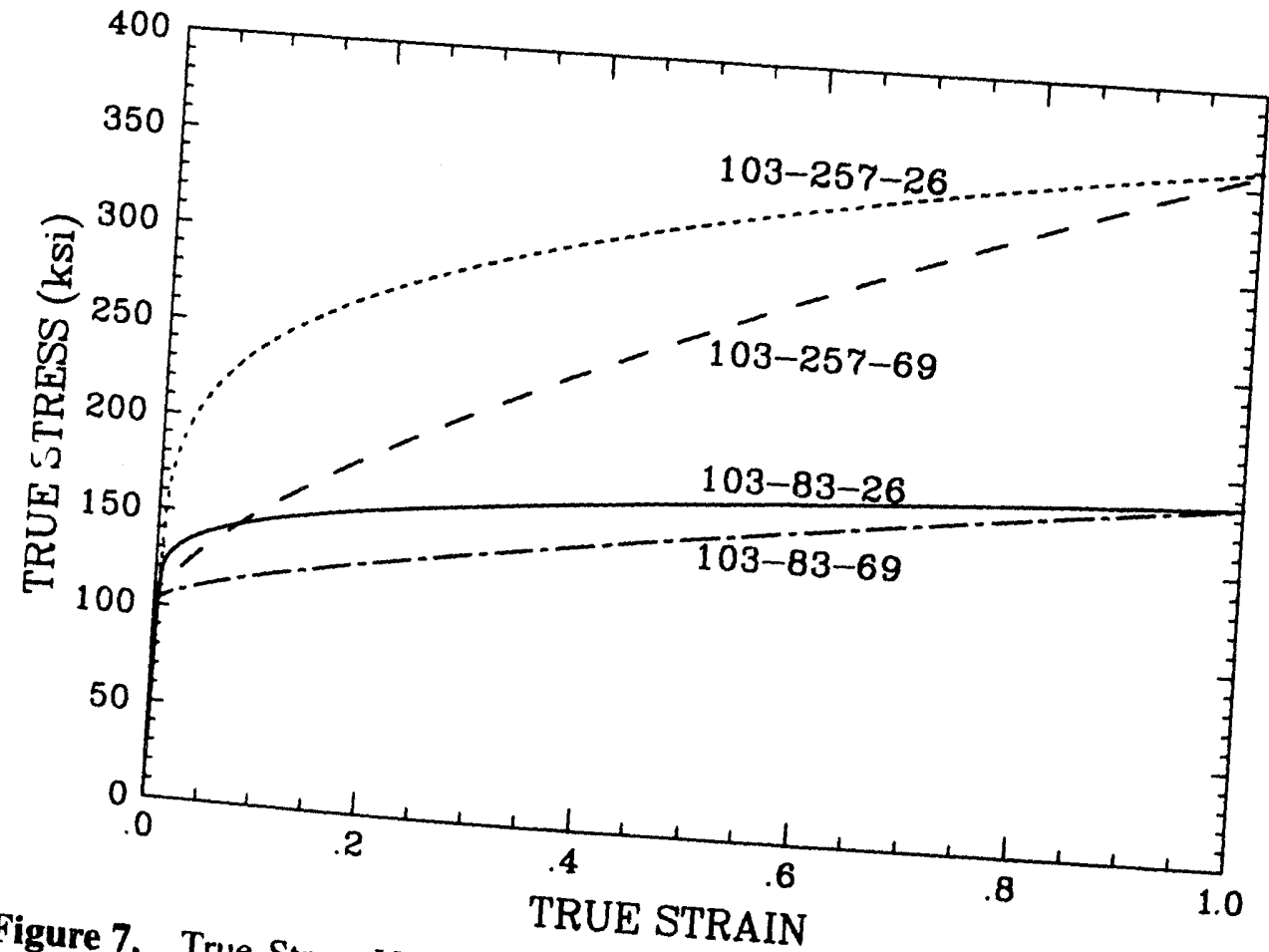
with a High Yield Strength
True-Stress Versus True-Strain Curves for the Material Parameters 


\subsection{Tearing Criterion}

In earlier work, several failure (initiation of a ductile tear) criteria were investigated [1]. These ranged from simple static values of stress and strain to very complicated, multiple parameter evolution equations. The most successful of these criteria, based on accurate prediction of failure initiation in the earlier study, was chosen for use here. This criterion was developed by researchers in the metal working industry[7]. It is a relatively simple evolution equation in which the plastic strain increment, scaled by a stress ratio, is accumulated until a critical value is reached at which point the initiation of ductile tearing is predicted.

$$
T P=\int_{0}^{\bar{\varepsilon}_{\mathrm{p}}} \frac{\left\langle 2 \sigma_{\mathrm{T}}\right\rangle}{3\left(\sigma_{\mathrm{T}}-\sigma_{\mathrm{m}}\right)} \mathrm{d} \bar{\varepsilon}_{\mathrm{p}}
$$

where:

$$
\begin{aligned}
& \bar{\varepsilon}_{p} \text { is the plastic strain, } \\
& \sigma_{T} \text { is the maximum principal stress, and } \\
& \sigma_{m} \text { is the mean (hydrostatic) stress. }
\end{aligned}
$$

As implemented here[8], the integral accumulates value with plastic strain only when the maximum principal stress is positive as indicated by the pointed brackets, \langle\rangle , which represent the Heaviside function. Thus, plastic strain with a negative maximum principal stress causes no change in the value of TP. Also, a high mean stress causes the value of TP to increase more rapidly with plastic strain, representing the well known effect of decreased ductility in metal alloys in the presence of hydrostatic tension. The critical value of TP is established by performing an analysis of a tensile test. TP is then evaluated using the computed stress state and substituting the strain-to-failure, $\bar{\varepsilon}_{f}$, as the upper integration limit. This provides a critical value of TP which can then be used to predict failure in other analyses. The strain-to-failure can be computed from the reduction-in-area, a ductility measure available from a standard tension test. The results from a typical tension test analysis are shown in Figure 8 . These analytical results show the determination of the critical tearing parameter for the material with a yield strength of $103 \mathrm{ksi}$, a hardening constant of $83 \mathrm{ksi}$, a hardening exponent of 0.26 , and a strain-to-failure of 1.27. In Figure 8, the maximum value of plastic strain is 1.27 (defined as failure for a tension test specimen), which corresponds to a maximum value of the tearing parameter of 1.693. The difference between these two values indicates the effect of the stress state caused by the necking in the specimen. In this case, the stress state deviated significantly from uniaxial tension because of specimen necking. Five levels of strain-to-failure were run. The majority of the analyses were conducted with a value of either 0.33 or 1.27 . An intermediate value of 0.8 along with extremes of 0.1 and 1.5 were also employed. Because of the nature of the tearing parameter used (plastic strain scaled by a stress ratio), the strain-tofailure parameter by itself does not completely define failure of a material. The other constitutive parameters also contribute to the critical value of the tearing parameter, necessitating the analysis of a tensile test specimen described above. The critical value of the tearing parameter for all combinations of material parameters is shown in Table 1 


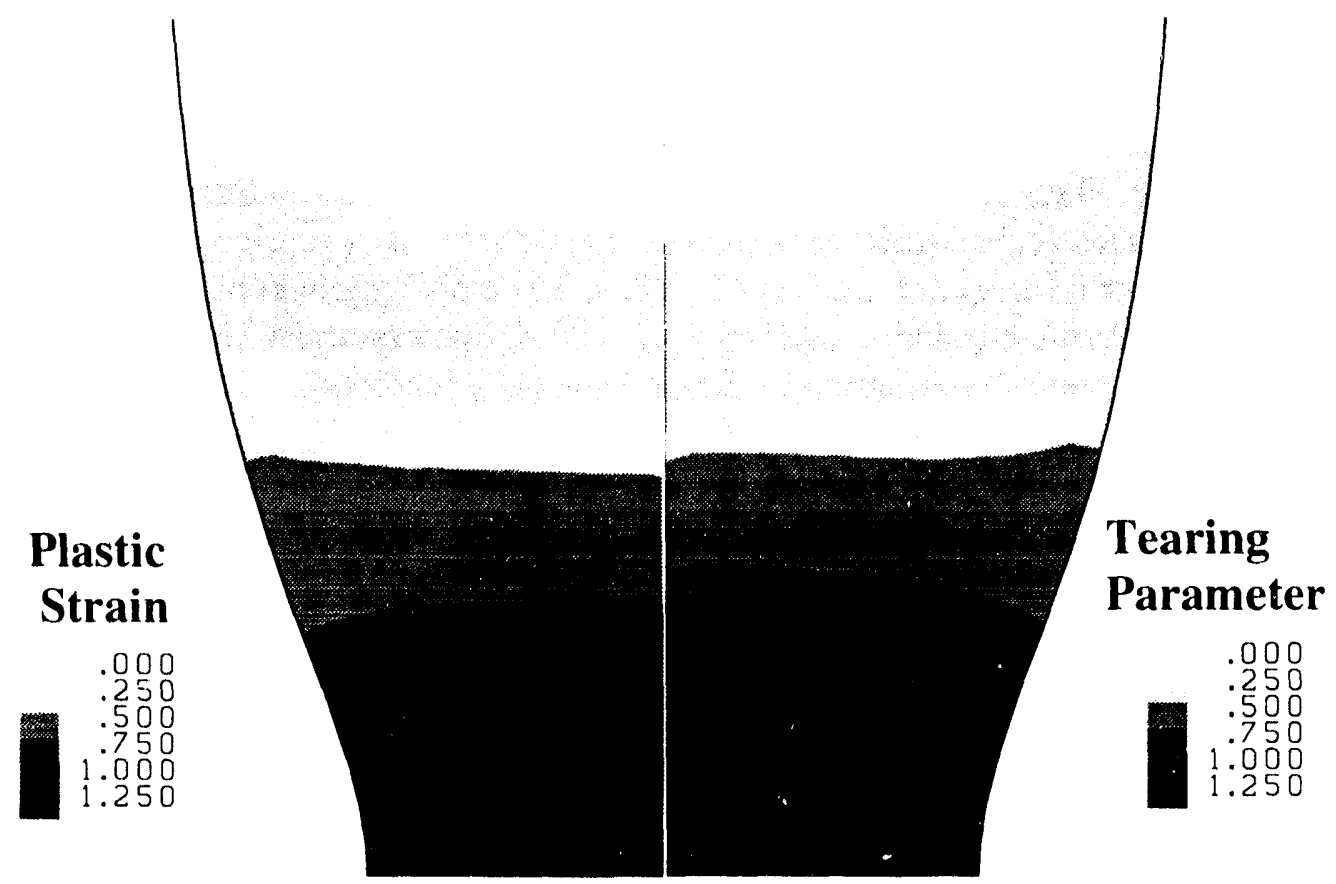

Figure 8. Contours of Plastic Strain and Tearing Parameter at Failure for a Tensile Test with a Yield Strength of $103 \mathrm{ksi}$, a Hardening Constant of $83 \mathrm{ksi}$, a Hardening Exponent of 0.26 , and a Strain-to-Failure of 1.27

The parameter list for the matrix of experiments (97 finite element analyses) depicting the entire range of geometric and materials parameters investigated is included in Appendix A. 
Table 1: Critical Value of the Tearing Parameter

\begin{tabular}{|c|c|c|c|c|}
\hline$\sigma_{y s}$ & A & $\mathrm{n}$ & $e_{f}$ & $\mathrm{TP}$ \\
\hline 20 & 170 & 0.48 & 0.8 & 0.8531 \\
\hline 37 & 83 & 0.26 & 0.33 & 0.3466 \\
\hline 37 & 83 & 0.26 & 1.27 & 1.600 \\
\hline 37 & 83 & 0.69 & 0.33 & 0.3325 \\
\hline 37 & 83 & 0.69 & 1.27 & 1.419 \\
\hline 37 & 257 & 0.26 & 0.33 & 0.3397 \\
\hline 37 & 257 & 0.26 & 1.27 & 1.549 \\
\hline 37 & 257 & 0.69 & 0.33 & 0.3308 \\
\hline 37 & 257 & 0.69 & 1.27 & 1.358 \\
\hline 70 & 40 & 0.48 & 0.8 & 0.8409 \\
\hline 70 & 170 & 0.15 & 0.8 & 0.9715 \\
\hline 70 & 170 & 0.48 & 0.1 & 0.1003 \\
\hline 70 & 170 & 0.48 & 0.8 & 0.8733 \\
\hline 70 & 170 & 0.48 & 1.5 & 1.809 \\
\hline 70 & 170 & 0.8 & 0.8 & 0.8299 \\
\hline 70 & 300 & 0.48 & 0.8 & 0.8531 \\
\hline 103 & 83 & 0.26 & 0.33 & 0.3616 \\
\hline 103 & 83 & 0.26 & 1.27 & 1.693 \\
\hline 103 & 83 & 0.69 & 0.33 & 0.3506 \\
\hline 103 & 83 & 0.69 & 1.27 & 1.565 \\
\hline 103 & 257 & 0.26 & 0.33 & 0.3455 \\
\hline 103 & 257 & 0.26 & 1.27 & 1.599 \\
\hline 103 & 257 & 0.69 & 0.33 & 0.3309 \\
\hline 103 & 257 & 0.69 & 1.27 & 1.412 \\
\hline 120 & 170 & 0.48 & 0.8 & 0.8998 \\
\hline
\end{tabular}




\section{Finite Element Analysis Results}

It is convenient to separate the discussion of the results of the finite element analyses described in the prior section and in Appendix A into six different sections. A specific geometry and loading environment is discussed in each section. Three different geometries were analyzed: a truncated cone (Figure 2), a hemisphere (Figure 3), and a cylinder (Figure 4). Two different loading environments were generated by varying the punch diameter. The small diameter ( $1 \mathrm{inch}$ ) punch results in a loading environment referred to as puncture. The large diameter (10 inch) punch yields a crush loading environment. Each of the three geometries responds differently to the different loading environments.

\subsection{Truncated Cone Geometry - Puncture Loading Environment}

The truncated cone geometry is characterized by a 1 inch top diameter along with a relatively small ( 0.5 inch or less) side-to-top radius. The 1 inch diameter punch defines the puncture loading environment. The other geometric parameters do not alter the basic truncated cone shape. The basic structural response of the truncated cones to the puncture load was similar regardless of the values of the other geometric parameters or the material parameters. The cone inverted via a rolling hinge mechanism where the location of the hinge increased in diameter with punch displacement as shown in Figure 9.

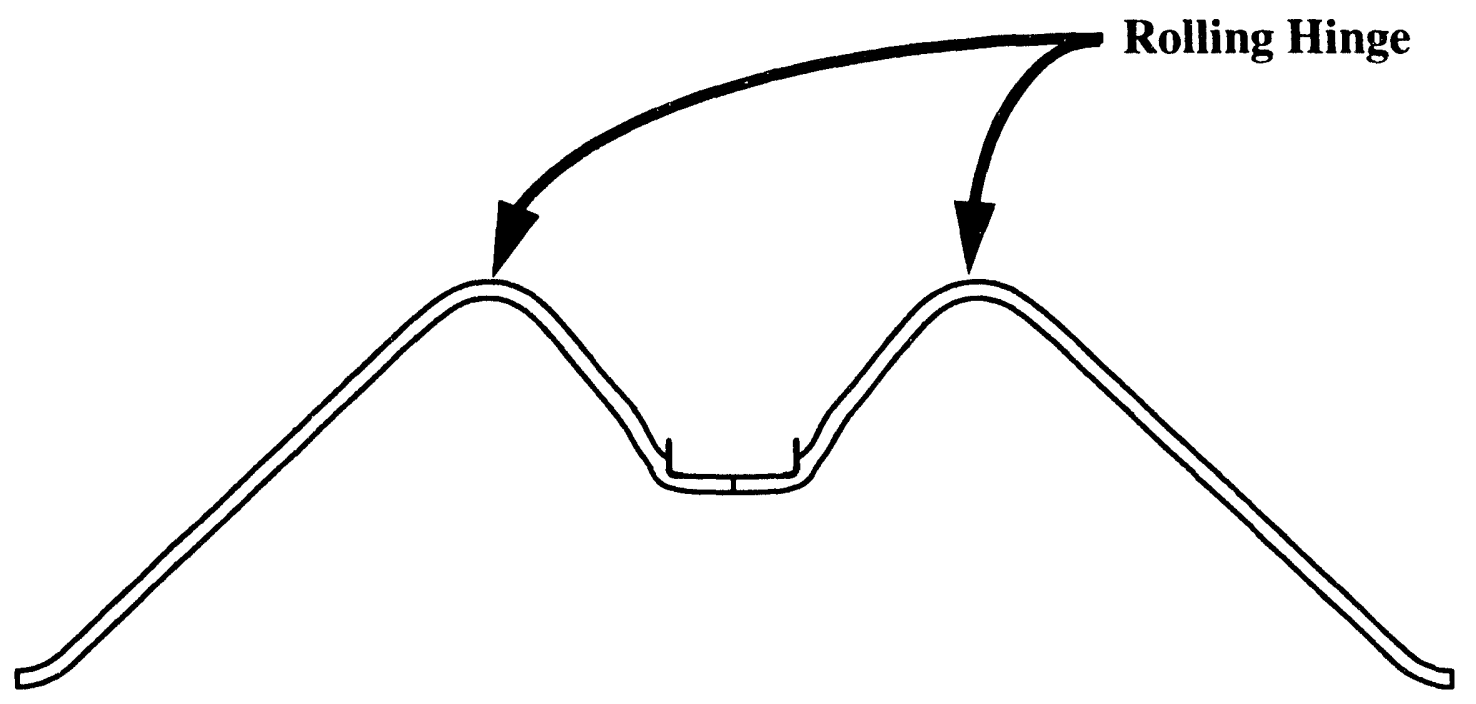

Figure 9. Deformed Shape of the Truncated Cone Loaded by the Small Diameter Punch Demonstrating a Rolling Hinge Mechanism

The rolling hinge deformation mechanism is relatively benign with only a modest increase in load required to propagate the hinge to larger diameters as the punch depth increases. The required loads did not reach levels which would cause localization (necking) of the region deforming around the punch. Therefore, failure was predicted only for the very low strain-tofailure materials. For all the intermediate and high strain-to-failure materials, the maximum punch displacement (i.e., the height of the cone) was reached without failure. 


\subsection{Truncated Cone Geometry - Crush Loading Environment}

The basic geometry described in Section 3.1 is used here. A ten inch diameter punch rather than a one inch diameter punch is used to provide a crush environment. The structural response is also the same as described in Section 3.1, a rolling hinge. The only failures occur with a small strain-to-failure value. These failures occur either at the bottom, fixed end of the cone or at the stress and strain concentration associated with a radical change in cross section where a thick top meets a thin side wall and the thickness change occurs over a short distance.

\subsection{Cylinder Geometry - Puncture Loading Environment}

The cylindrical geometry is produced by a combination of the large (10 inch) top geometry and a relatively small ( 0.5 inch or less) side-to-top radius. The 4 inch side-to-top radius never occurs along with the $10 \mathrm{inch}$ top diameter. In the puncture environment, failure occurs at a moderate value of punch displacement due to localization around the punch as shown in Figure 10. The stiff vertical cylinder walls provide both axial and radial constraint to the

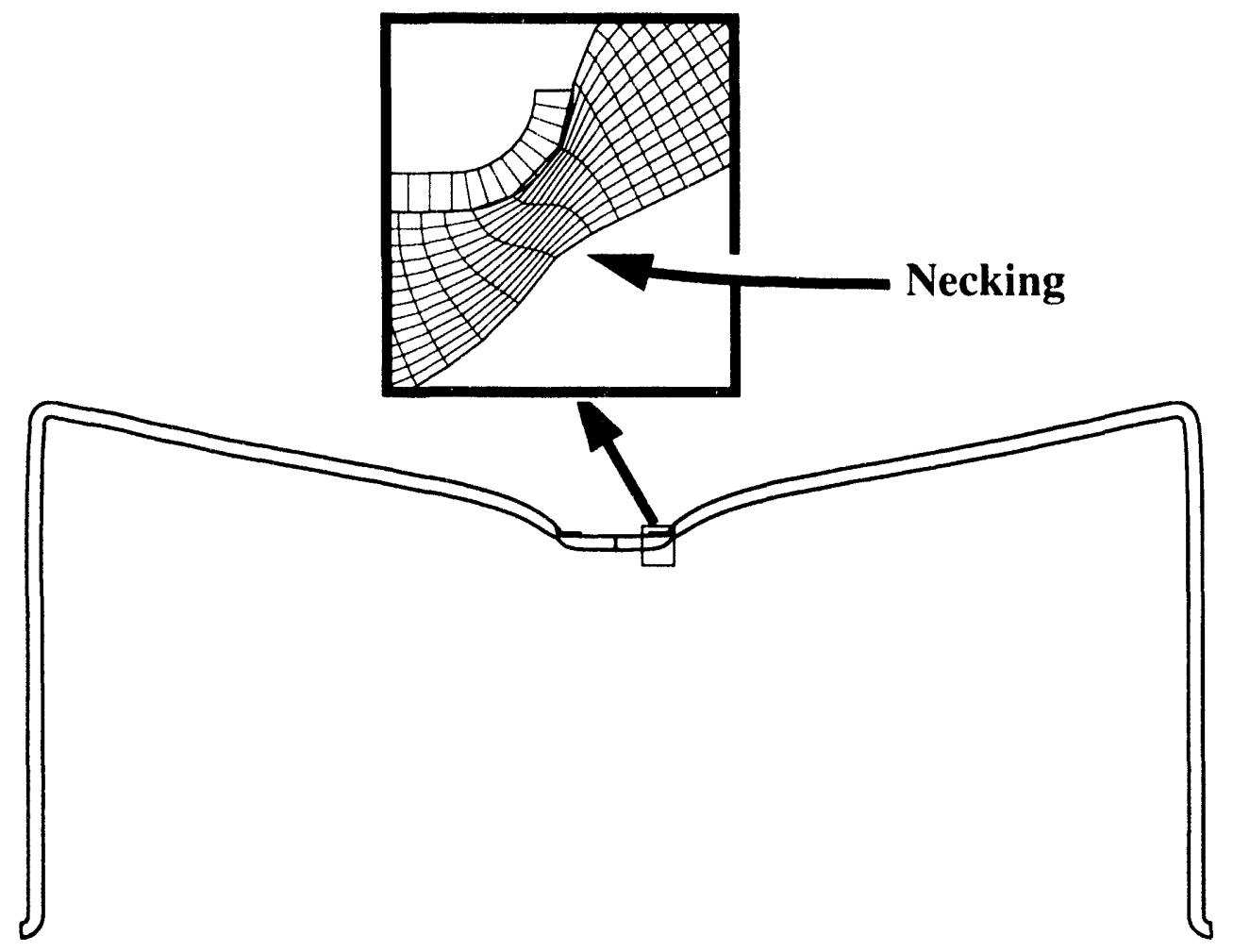

Figure 10. Deformed Shape of the Cylinder Loaded by the Small Diameter Punch Showing Localization Around the Punch

cylinder top. This constraint imposes a radial tensile stress on the cylinder top material which first necks and then fails. Only when the top of the cylinder has a much greater thickness than the side wall $\left(t_{t}-t_{s}=0.2\right.$ inch) are large punch displacements seen without failure. Large differences between top and side thickness implies a thin side wall. For those cases with large punch displacements to failure, the side wall either buckles or forms a rolling hinge near the fixed bottom end which relieves the axial load on the punch. 
Cylinder testing with the puncture loading environment (described in Section 5) indicates that circumferential buckling of the cylinder top can occur. After moderate punch displacement, significant hoop compression develops in the flat top of the cylinder. This deformation mode, which is not reproducible with two-dimensional, axisymmetric analysis techniques, reduces the structural stiffness and suppresses localization or the cylinder material around the punch. This buckling mechanism is not important for small punch displacements. However, it becomes more important for increasing punch displacement and can even lead to the complete suppression of localization and failure around the punch. Low values of computed punch displacements to failure in Appendix B can be regarded as accurate. Moderate to large values of computed punch displacement to failure are conservative. That is, experimentally measured results should be at least as large as those computed using two dimensional analysis techniques.

\subsection{Cylinder Geometry - Crush Loading Environment}

The same basic geometry described in Section 3.3 is used here. Only the punch diameter was changed to 10 inches to be consistent with the crush loading environment. There were more difficulties with the cylinder crush analyses than with any of the other geometries or environments. The cylinder crush is a relatively benign environment so that few early failures were encountered. Those that did occur were associated with the fixed, bottom end of the cylinder. For moderate to large punch displacements, the cylinder walls buckle into multiple tight folds, seen in Figure 11. A robust contact tracking algorithm capable of dealing with the

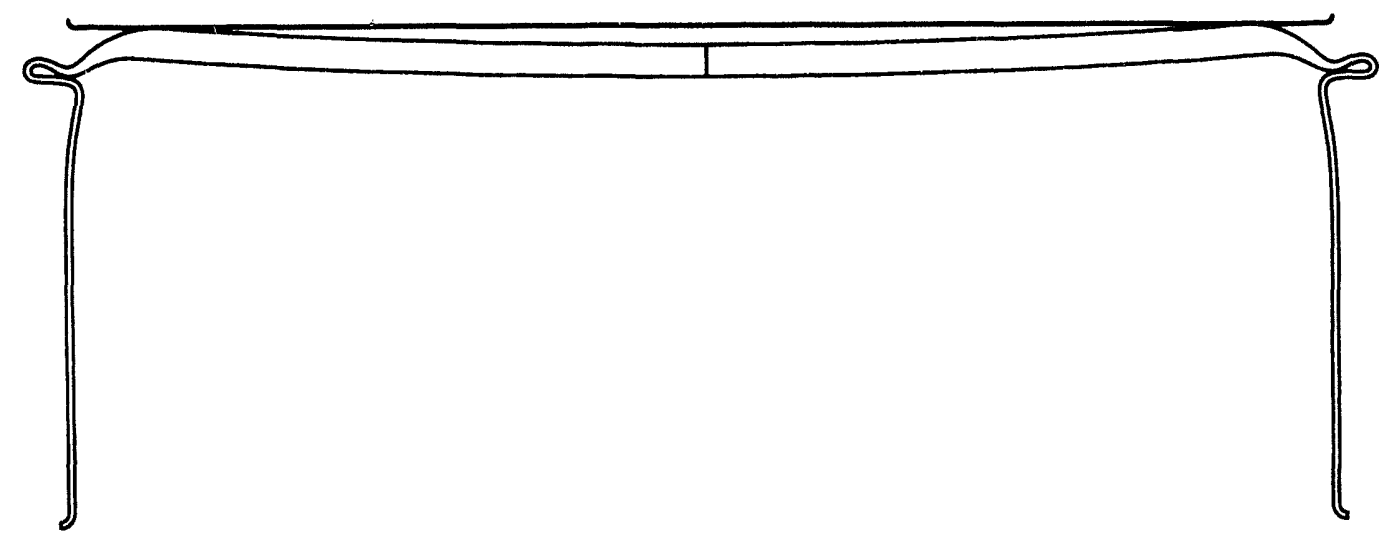

Figure 11. Deformed Shape of the Cylinder Loaded by the Large Diameter Punch Demonstrating Buckling of the Side Walls

multiple folds was not available in the quasistatic code. Therefore, there were cases of illegal contacts, mesh overlaps, or otherwise questionable analysis results. Research is currently underway to enhance the contact algorithms to better analyze this type of deformation[9].

\subsection{Hemisphere Geometry - Puncture Loading Environment}

The hemispherical geometry is attained with a small ( 1 inch) top diameter and a large ( 4 inch) top-to-side radius. The structure responds by forming a rolling hinge, similar to the truncated cone, early in the loading. As the puncture event proceeds, the rolling hinge progresses 
outwards on the side walls and the behavior begins to resemble that of the cylinder. As with the cylinder, the structural stiffness of the hemisphere plays a dominant roll in the type of failure. When the top and side walls have the same thickness, there is sufficient structural stiffness to force localization followed by failure around the punch. When the top is thicker than the side wall, localization around the punch does not occur and the only failures are associated with low values of strain-to-failure which do not require necking prior to failure. While qualitative similarities exist between the cylinder and the hemisphere, the hemisphere is a more tolerant geometry. Failures preceded by necking never occur at low punch displacements (the earliest is a punch displacement of 1.55 inches with all the rest at punch displacements greater than 2.3 inches).

As discussed for the cylinder punch environment, the post analysis testing described in Section 5 shows that buckling due to hoop compression occurs for large punch displacements. This effect occurs at much larger punch displacements for the hemispheres than for the cylinders. However, localization and failure also occur at higher values of punch displacement. Again, the two-dimensional, axisymmetric analyses should be considered a lower bound (conservative result) on punch displacement to failure.

\subsection{Hemisphere Geometry - Crush Loading Environment}

The same hemisphere geometry described in Section 3.5 was used with a large (10 inch) diameter punch for the crush environment. This is a very benign environment. The only failures with this combination of geometry and loading occurred with low values of strain-tofailure. These failures only occurred at the bottom, fixed boundary condition or with a mesh overlap similar to those experienced with the cylinder discussed in Section 3.4. 


\section{Statistical Analysis}

\subsection{Experimental Design}

A fractional factorial design was used to specify the levels for the ten parameters to be varied in this study[2]. A factorial experimental design is an efficient means for estimating the individual and joint effects of a number of parameters on one or more responses. The individual effects are called main effects, and the twu-way joint effects are called two-way interaction effects, or simply interaction effects. Two levels, high and low, are chosen to cover a range of interest for each quantitative parameter. In a full factorial experiment, the response is measured or evaluated for all combinations of levels of all parameters. Thus if there are $n$ parameters, $2^{\mathrm{n}}$ evaluations are required. When the number of parameters exceeds five, and resources do not allow evaluating all parameter combinations, a fraction of a full factorial design is often used. The fractional factorial design is selected so that the parameter effects of interest, usually all main effects and some or all two-way interactions, are separately estimable. The higher level interaction effects will then be confounded with the main effects and two-way interaction effects. Often, however, the higher level interaction effects are small relative to the lower order effects and can safely be ignored.

For the initial phase of this study, a subset, $2^{10-4}=64$ parameter combinations, of the total number of possible combinations, $2^{10}$, was selected. This subset represents a $1 /(2)^{4}$ fraction of the full $2^{10}$ factorial design. This particular subset was chosen so that the main effects of the factors could be estimated, and so that the 2-way interactions were not confounded with the main effects. The 2-way effects may, however, be confounded with each other. This type of design is said to be of resolution IV. In addition, eight 'axial' runs for the four material parameters, plus one intermediate run were made, for a total of 73 runs. Axial runs are runs where one parameter is set to an extreme, and all other parameters are set to their center values. For each of the four material properties, two axial runs were made, at low and high extremes. In a center run, all parameters are set at their center values. The purpose of including axial and center runs is to determine the extent of nonlinearity in the response for the selected parameter settings.

In this design, none of the main effects are confounded with each other or with any two-way interaction. However, the two-way interactions can be confounded with each other and with higher order interactions. Thus if the analysis showed that an interaction term was significant, it is not possible to determine which of the confounded interaction terms were actually influential. Thus, as in the current work, follow-on studies are usually performed with the parameters having the most important main effects. After the follow-on study is completed, a more detailed model can be constructed of the parameter effects on the response(s).

When the first 73 runs were completed, the important parameters affecting the displacement at failure were determined from an analysis of variance (ANOVA). Although there is no source of random variation in these computer runs, ANOVA is still a useful technique because it can identify important sources of variation in the presence of unimportant sources, and/or random variation. A linear model with cross-product terms was fit to the data to determine which of the ten factors most strongly influenced the results[3]. This model was not sufficiently detailed to permit predictions of punch displacement to failure but did allow selection of the five most important parameters for further study. In order of importance, these parameters 
were determined to be: $\varepsilon_{f}, b, r_{s t}, D_{p}, \sigma_{y s}$.

In the follow-on experiment, 24 additional runs were made, holding the less important parameters $t_{s}, t_{t}-t_{s}, r_{s b}, A$, and $n$ constant. Levels for the other five more influential parameters were selected to provide additional intermediate and bounding values. Table $A 1$ is a list of the parameter settings for all 97 runs. Table B1 contains the response computed from the finite element analysis, the punch displacement at failure, for all runs.

Using the data from all 97 runs, we sought to develop insights about combinations of geometric and material properties that lead to high displacements at failure, and conversely, about combinations that lead to low displacements at failure[10]. Because the two punch sizes ( 1 and 10) exert very different stresses on the barrier, the form of the insights differ between these two cases. A methodology for this analysis is given in the next section.

\subsection{Regression Trees}

A statistical methodology called CART (Classification and Regression Trees)[11] was used to construct 'optimal' binary regression trees to divide, or split, the data into groups, based on the values of a selected subset of the parameters. The group center is given by the median response, and the degree of group clustering is given by the mean absolute deviation of the response. The subset of parameters and levels defining the regression tree are chosen so that the resuiting groups have minimum average absolute deviation about the response median of the group. As a result, responses within a single group are more closely clustered than responses from different groups.

The order of the parameters in the tree is an indicator of their importance since, at each step, the parameter and level are selected to produce the greatest clustering in the response. The level chosen for the split is an average of the two nearest values of the parameter that produces the greatest reduction in mean absolute deviation. There are different rules by which the user may tell the algorithm when to stop splitting. For this analysis, the stopping rule was that a node with fewer than ten cases could not be split. The longer the regression tree, the more (apparently) accurate is the prediction. However, the results are less useful to summarize the significant features of the data, because the tree is more complex.

Figure 12 and Figure 13 contain the regression trees for $D_{p}=1$ (puncture) and $D_{p}=10$ (crush). For a specified set of values for the ten parameters, one can use the tree to get a (rough) prediction of the displacement at failure. As an example of the use of a regression tree for $D_{p}=1$, consider the set of parameter values indicated by run 17 in Table $A 1$. We enter the regression tree of Figure 12 at the top. The value for $\varepsilon_{f}$ is 0.33 , so we proceed down the left branch. Since the value for $b$ is 1 , we proceed down the left branch again. Since $r_{s t}=4.0$, we now take the right branch, and determine that this set of parameters belongs to the terminal group with a median displacement of 1.2. If we had not already made this run, we would estimate the displacement to be 1.2 for this parameter set. From Figure 12 we can see that the second, third, fourth, and sixth groups, with median displacements of 1.2, 0.9, 1.0, and 1.8, are 'middling' groups. The first group, with a median displacement of 0.20 , is a low group. The fifth and seventh groups, with median displacements of 4.5 , are high groups. 


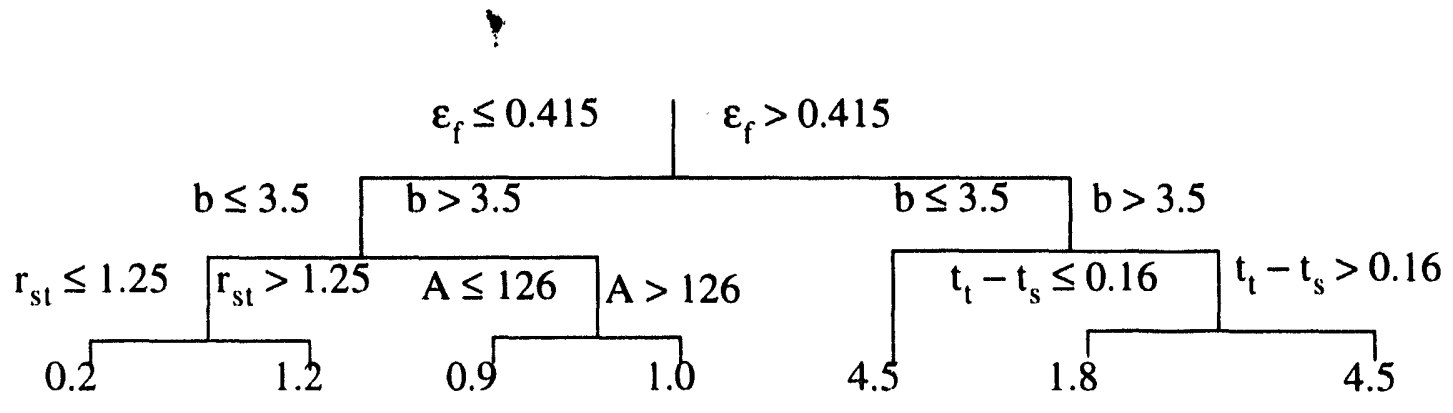

Median displacement at failure (inch) for the group

Figure 12. Regression Tree Diagram for the Puncture Environment ( $D=1$ inch)

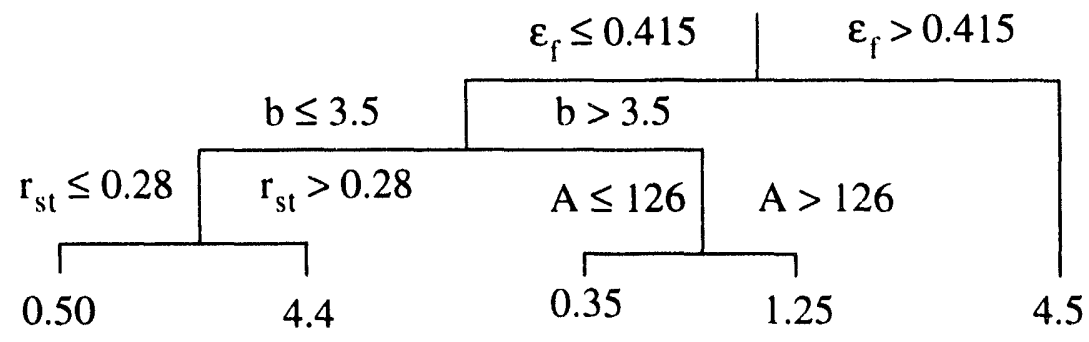

Median displacement at failure (inch) for the group

Figure 13. Regression Tree Diagram for the Crush Environment ( $D=10$ inch)

One can refer to Figure 12 and Figure 13 to determine how to achieve the best results (highest displacement to failure) in either a puncture or crush environment, and how to avoid the worst results (lowest displacement to failure). For high displacement in a puncture environment, $\varepsilon_{\mathrm{f}}$ should be greater than 0.415 , and $b$ (top diameter) should be less than 3.5 , leading to the fifth group. If $b$ is large $(>3.5)$, then $t_{t}-t_{s}$, the top thickness minus the side thickness, should be greater than 0.16 , leading to the seventh group. The value 0.415 for $\varepsilon_{f}$ is the average of 0.33 and 0.5 , at which runs were actually made. The value of 3.5 for $b$ is the average of 1 and 6 . The value of 0.16 for $\mathrm{t}_{\mathrm{t}}-\mathrm{t}_{\mathrm{s}}$ is the average of 0.125 and 0.20 . For high displacement in a crush environment (Figure 13), either $\varepsilon_{\mathrm{f}}$ should be greater than 0.415 , leading to the fifth group, or if $\varepsilon_{\mathrm{f}}$ is less than 0.415 , then $b$ should be less than 3.5 , and $r_{s t}$ should be greater than 0.28 , the average of 0.063 and 0.5 , leading to the second group.

One can compare the two regression trees to determine what parameter settings might be helpful in either environment. In general, high values of $\varepsilon_{f}(>0.415)$ are beneficial in either a puncture or crush environment. In a puncture environment, if $b$ is large $(>3.5)$, then $t_{t}-t_{s}$ must be greater than 0.16 . That is, in a puncture environment, if the top diameter is large, the top should be thicker, even if the true strain to failure is high. From the figures we can see that the puncture environment is more demanding than the crush environment.

For lower values of $\varepsilon_{f}(<0.415)$ in a crush environment, very high displacements $(>4.4)$ can 
still be achieved if $b$, the top diameter, is low $(<3.5)$ and $r_{s t}$, the side-to-top radius, is 0.5 or 2 . Somewhat lower values are obtained if $r_{s t}$ equals 4 . Thus, in a crush environment, the right combination of geometric properties can compensate for an important material property, low strain to failure. However, this compensation is not nearly so effective in :s puncture environment. It is generally preferable to have lower values of $b$, the top diameter.

In summary, the most important parameter for either a puncture or crush environment is $\varepsilon_{\mathrm{f}}$, the true strain to failure. Increasing the value of $\varepsilon_{\mathrm{f}}$ is the most effective and direct means of improving the resistance to failure by tearing. After the strain-to-failure has been considered, the geometry can play a part. Certain geometric adjustments can create conditions in which strain localization and subsequent early failure is suppressed.

\subsection{Predictive Model}

Using the insights gained from construction of the regression trees, a predictive model based on 88 of the 97 calculations was developed[12]. These 88 calculations had the punch diameter set to 1 or 10 inches. The remaining 9 calculations, with punch diameter set to 5 inches, were used partly as a check of the prediction.

Because of the nonlinear nature of the displacement response, it was not possible to fit a single model to the data. Thus, the model consists of four different equations, to be used depending on whether the punch diameter $D_{p}$ is 1 (puncture environment) or 10 (crush environment), and whether the true strain to failure is less than 0.5 , or greater than or equal to 0.5 . Different models are required for these situations because if the material property $\varepsilon_{\mathrm{f}}$ is sufficiently high, this alone is often sufficient, especially in a crush enviionment, to produce high displacements at failure. However, when $\varepsilon_{f}$ is lower, the top diameter $b$ and the thickness difference $t_{t}-t_{s}$ and the power law coefficient A can be traded off for the lower strain to failure.

\subsection{Predictive Model Development}

The predictive models were developed as follows. Since the response is restricted to be between 0 and 4.6, a transform was used on this interval. The transformed response was the base 10 logarithm of $\left(\delta_{p} /\left(4.6-\delta_{p}\right)\right)$, where $\delta_{p}$ is the displacement at failure. The explanatory variables were also transformed; again using the base 10 logarithm. For each of the four cases, a model was fitte 1 to the transformed independent and dependent variables, using linear and cross-product terms. Sirice the four cases are defined by the values of $D_{p}$ and $\varepsilon_{f}$, the transforms of these variables do not appear in the models; the effect of these variables is implicit in the coefficients calculated for the other terms. The predicted value $\left(\delta_{p}\right)$ for the transformed response must be converted back to the interval $(0,4.6)$. The appropriate conversion is the inverse of the transform: $\delta_{p}=4.6 \times\left(10^{\mathrm{x}}\right) /\left(1+10^{\mathrm{x}}\right)$.

\subsection{Equations}

The four-part predictive model involves the following calculations. The function $\log (\mathbf{x})$ represents the base 10 logarithm of $x$.

If $D_{p}=1$ and $\varepsilon_{f}<0.5$ (i.e., a low strain-to-failure material in a puncture environment), perform the following calculation for the predicted displacement, $\delta_{p}$ : 


$$
\begin{gathered}
x=3.4934+12.7306 \times \log \left(t_{s}\right)+0.30146 \times \log (b)-1.09237 \times \log \left(r_{s t}\right) \\
+1.07796 \times \log (A)-0.35349 \times \log \left(r_{s t}\right) \times \log (b) \\
+0.72325 \times \log \left(r_{s t}\right) \times \log (A)+5.93828 \times \log \left(t_{s}\right) \times \log \left(t_{s}\right) \\
\delta_{p}=4.6 \times \frac{10^{x}}{1+10^{x}}
\end{gathered}
$$

If $D_{p}=1$ and $\varepsilon_{f} \geq 0.5$ (i.e., a high strain-to-failure material in a puncture environment), perform the following calculation for the predicted displacement $\delta_{p}$ :

$$
\begin{gathered}
x=6.35222+13.9583 \times \log \left(\max \left(t_{t}-t_{s}, 0.01\right)\right)+2.20527 \times \log (b) \\
-6.78425 \times \log \left(r_{s t}\right)-0.25939 \times \log (A) \\
+3.64758 \times \log \left(\max \left(t_{t}-t_{s}, 0.01\right)\right) \times \log \left(\max \left(t_{t}-t_{s}, 0.01\right)\right) \\
+0.42754 \times \log \left(r_{s t}\right) \times \log \left(r_{s t}\right)-2.06189 \times \log \left(\max \left(t_{t}-t_{s}, 0.01\right)\right) \times \log (A) \\
+2.24174 \times \log \left(\max \left(t_{t}-t_{s}, 0.01\right)\right) \times \log (b) \\
+3.37037 \times \log \left(r_{s t}\right) \times \log (A)+0.42057 \times \log \left(r_{s b}\right) \times \log \left(r_{s t}\right) \\
\delta_{p}=4.6 \times \frac{10^{x}}{1+10^{x}}
\end{gathered}
$$

If $D_{p}=10$ and $\varepsilon_{f}>0.5$ (i.e., a crush environment with a low strain-to-failure material), perform the following calculation for the predicted displacement $\delta_{p}$ :

$$
\begin{gathered}
x=-5.98937-3.02057 \times \log \left(\max \left(t_{t}-t_{s}, 0.01\right)\right)-6.9967 \times \log (b) \\
-13.77734 \times \log \left(r_{s t}\right)+0.68447 \times \log (A) \\
+4.67820 \times \log \left(\max \left(t_{t}-t_{s}, 0.01\right)\right) \times \log (b) \\
+0.60930 \times \log \left(\max \left(t_{t}-t_{s}, 0.01\right)\right) \times \log \left(r_{s t}\right) \\
+6.12833 \times \log (b) \times \log (A)+6.94738 \times \log \left(r_{s t}\right) \times \log (A) \\
\delta_{p}=4.6 \times \frac{10^{x}}{1+10^{x}}
\end{gathered}
$$

If $D_{p}=10$ and $\varepsilon_{f} \geq 0.5$ (i.e., a crush environment with a high strain-to-failure material), perform the following calculation for the predicted displacement $\delta_{\mathrm{p}}$ : 


$$
\begin{gathered}
x=99.3986+8.35578 \times \log \left(\max \left(t_{t}-t_{s}, 0.01\right)\right)-1.21805 \times \log (b) \\
-1.63941 \times \log \left(r_{s t}\right)-86.04519 \times \log (A) \\
+2.99239 \times \log \left(\max \left(t_{t}-t_{s}, 0.01\right)\right) \times \log \left(\max \left(t_{t}-t_{s}, 0.01\right)\right) \\
-1.46110 \times \log \left(r_{s t}\right) \times \log \left(r_{s t}\right)+19.87641 \times \log (A) \times \log (A) \\
-0.95735 \times \log \left(r_{s t}\right) \times \log \left(r_{s b}\right) \\
\delta_{p}=4.6 \times \frac{10^{x}}{1+10^{x}}
\end{gathered}
$$

\subsection{Comparison of Predictions}

Tables $\mathrm{Cl}$ and $\mathrm{C} 2$, in Appendix $\mathrm{C}$, give results of the predictions of the four-part model. The column labeled $\delta_{c}$ contains the displacement to failure computed from the finite element analysis, and the column labeled $\delta_{\mathrm{p}}$ contains the displacement to failure predicted using Equations 3 to 10 . No model was developed for the intermediate punch diameter, $D_{p}=5$. However, the results of predictions using all four equations of the model were evaluated for the 9 calculations with $\mathrm{Dp}=5$. In this case it appears that none of the predictions are very good, since they were developed for either a puncture $\left(D_{p}=1\right)$ or a crush $\left(D_{p}=10\right)$ environment. However, the fourth equation, for $D_{p}=10$ and $\varepsilon_{f}>0.5$, is marginally better than the others. The predicted displacement at failure is plotted against the finite element computed value in Figure 14 and Figure 15 for the puncture and crush environments respectively.

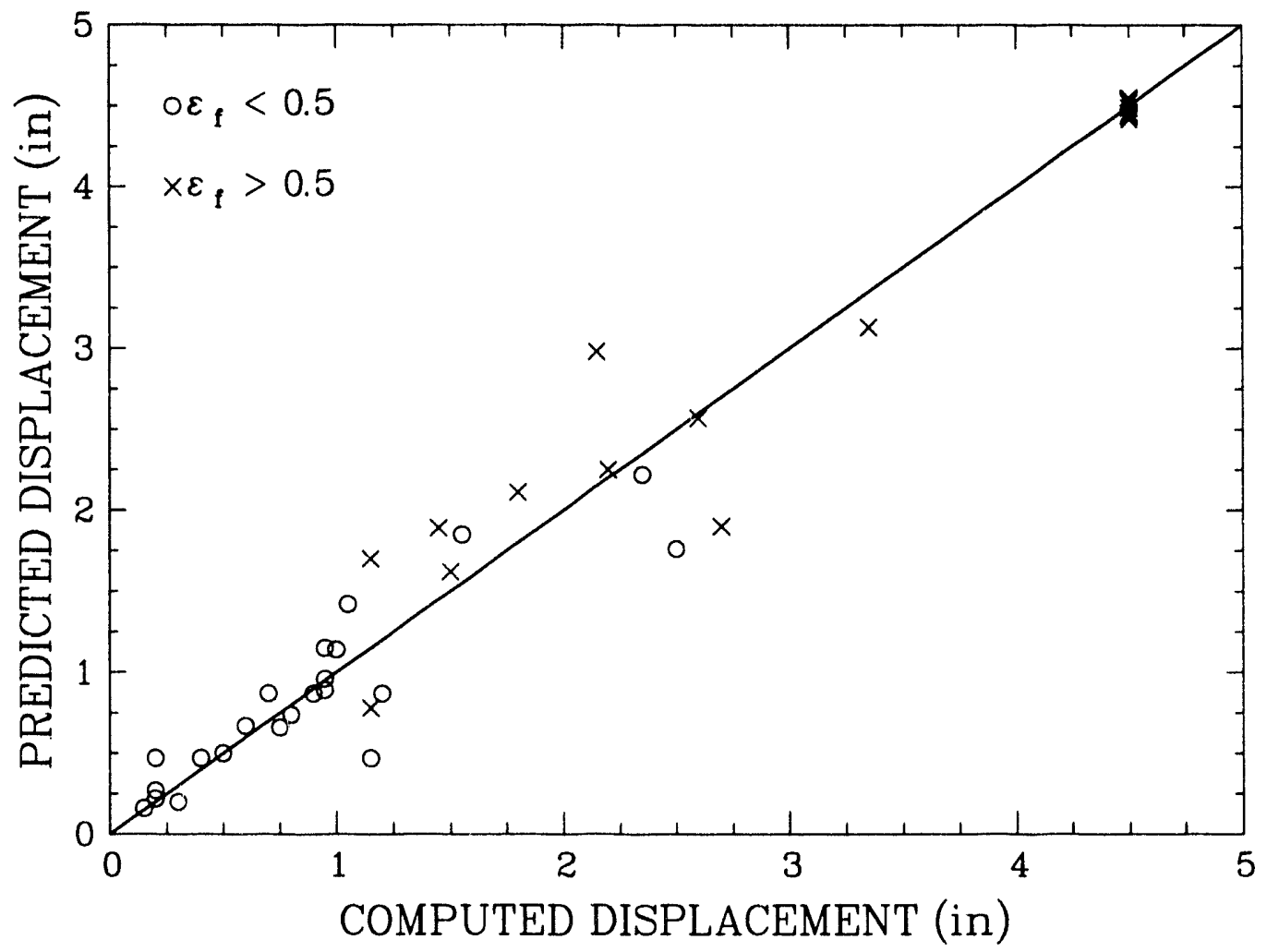

Figure 14. Comparison Between the Predicted and Computed Displacement to Failure for the Puncture Environment 


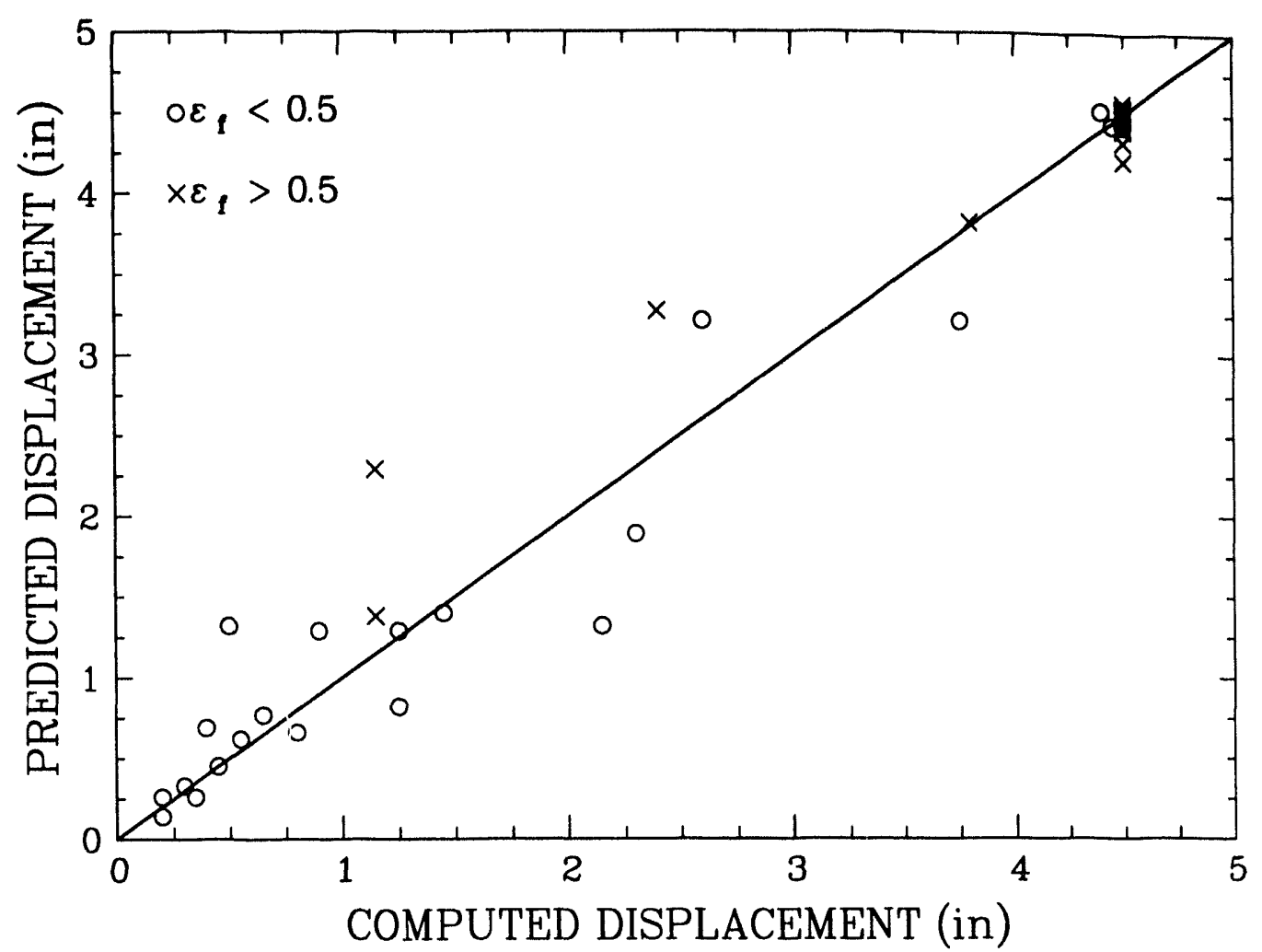

Figure 15. Comparison Between the Predicted and Computed Displacement to Failure for the Crush Environment

From these plots one can see that the prediction is best for displacements that are either very low or very high. These plots show that the prediction is reasonably good for these calculations. One must keep in mind that the models were developed from these calculations, and thus in general their predictive ability for other parameter combinations may not be as good as the plots indicate. The user of these models should also keep in mind that they were developed for particular, simplified geometries that may not adequately incorporate critical aspects of other geometries such as those found in real firesets. In these calculations, the force was applied in a downward direction, in the middle of the top. There were no interior structures to resist the force. The model will predict a displacement no greater than 4.6 inches, because it was developed for such a geometry. Work is ongoing to extend this study to internal components and other geometries.

\subsection{Summary}

A four part model, based on the results of 88 calculations, was developed to provide guidance for designers and nuclear safety analysts on the effects of material and structural properties on the ability of a generic barrier to resist tearing under the downward motion of a punch located at the top. The generic barrier was represented by a truncated cone whose top diameter, side and top thicknesses, and side-to-top and bottom-to-top radii were varied. The material properties were modeled by a power law constitutive relationship, whose parameters are yield stress, hardening constant, hardening exponent, and true strain to failure. 
Based on the regression trees developed for the puncture and crush environments, a four part predictive model was developed using linear regression. Four parts were necessary because of the decidedly nonlinear relationship between the punch displacement to failure and the structural and material properties. The appropriate equation is chosen based on whether a puncture or crush environment is present, and whether the true strain to failure is less than 0.5 , or greater than or equal to 0.5 . The predictive ability of the model is demonstrated with tables and plots using the calculations made for the study. These predictions may be used to provide insights into design, but should not be considered a substitute for a detailed finite element analysis of an actual barrier. 


\section{Confirmatory Tests}

Nine tests were run to assess the accuracy of the finite element modeling. These tests consisted of specimens with three geometries of three materials each. The geometries were similar to those described in Section 2, a cylinder, a hemisphere, and a truncated cone. The specimens $w^{\prime}$ se a nominal 5 inches high with a nominal base diameter of 10 inches. Specimen thicknesses ranged from 0.053 inch to 0.092 inch. The three materials selected were 304 stainless steel, 6061-T6 aluminum, and 6061-T0 aluminum. All specimens were heat treated after fabrication to minimize the effects of deformation history or residual stresses on the materials response. The individual test specimen dimensions are shown in Table 2 along with the materials properties in Table 3.

Table 2: Specimen Geometry for the Confirmatory Tests

\begin{tabular}{|l|l|l|l|l|}
\hline Shape & Height (in) & Bottom Dia (in) & Thickness (in) & Material \\
\hline \hline Cone & 5.065 & 9.969 & 0.076 & 304 \\
\hline Cone & 5.037 & 10.313 & 0.080 & $6061-$ T6 \\
\hline Cone & 5.084 & 10.313 & 0.081 & $6061-$ T0 \\
\hline Cylinder & 5.043 & 10.070 & 0.053 & 304 \\
\hline Cylinder & 4.970 & 10.045 & 0.071 & $6061-$ T6 \\
\hline Cylinder & 4.988 & 10.044 & 0.073 & $6061-$ T0 \\
\hline Hemisphere & 4.950 & 10.040 & 0.092 & 304 \\
\hline Hemisphere & 4.968 & 10.063 & 0.071 & $6061-$ T6 \\
\hline Hemisphere & 5.023 & 10.016 & 0.073 & $6061-$ TO \\
\hline
\end{tabular}

Table 3: Materials Properties for the Confirmatory Tests

\begin{tabular}{|l|l|l|l|l|l|}
\hline Material & E (psi) & $v$ & $\sigma_{\text {ys }}$ (psi) & A (psi) & $n$ \\
\hline \hline 304 Stainless & $28,000,000$ & 0.27 & 28,000 & 192,746 & 0.7482 \\
\hline 6061-T6 Aluminum & $9,900,000$ & 0.33 & 42,000 & 29,964 & 0.3406 \\
\hline 6061-T0 Aluminum & $9,900,000$ & 0.33 & 4,250 & 32,702 & 0.3257 \\
\hline
\end{tabular}


All specimens were tested in a closed loop servo-hydraulic testing machine, run under stroke control, with the bottom end resting on a flat platen and the load applied through a 1-1/4 inch diameter steel rod with a 1/8 inch chamfer. An in-line load cell provided the specimen load. The testing machine is stiff compared to the test specimens so that the actuator displacement was used to measure the specimen displacement. The tests were terminated at the stroke limit of the machine or when the initiation of tearing was suspected (typically an audible ping from the specimen). After the test, the specimens were sectioned and photographed.

All nire specimens were analyzed using two-dimensional, axisymmetric assumptions similar to the analyses explained in detail in Section 3. The computed load versus displacement curves are compared to the measured curves in Figure 16 through Figure 24. The computed deformed shapes are also compared to the post-test photographs in these figures. The predicted values at the initiation of tearing based on the minimum and maximum ductility measured in standard tensile tests are marked on the computed load versus displacement curves. For those specimens which demonstrated tearing prior to the stroke control limit, the end of the measured load versus displacement curve is marked by a diamond. The curves for specimens which tolerated the maximum machine stroke without tearing are unmarked.

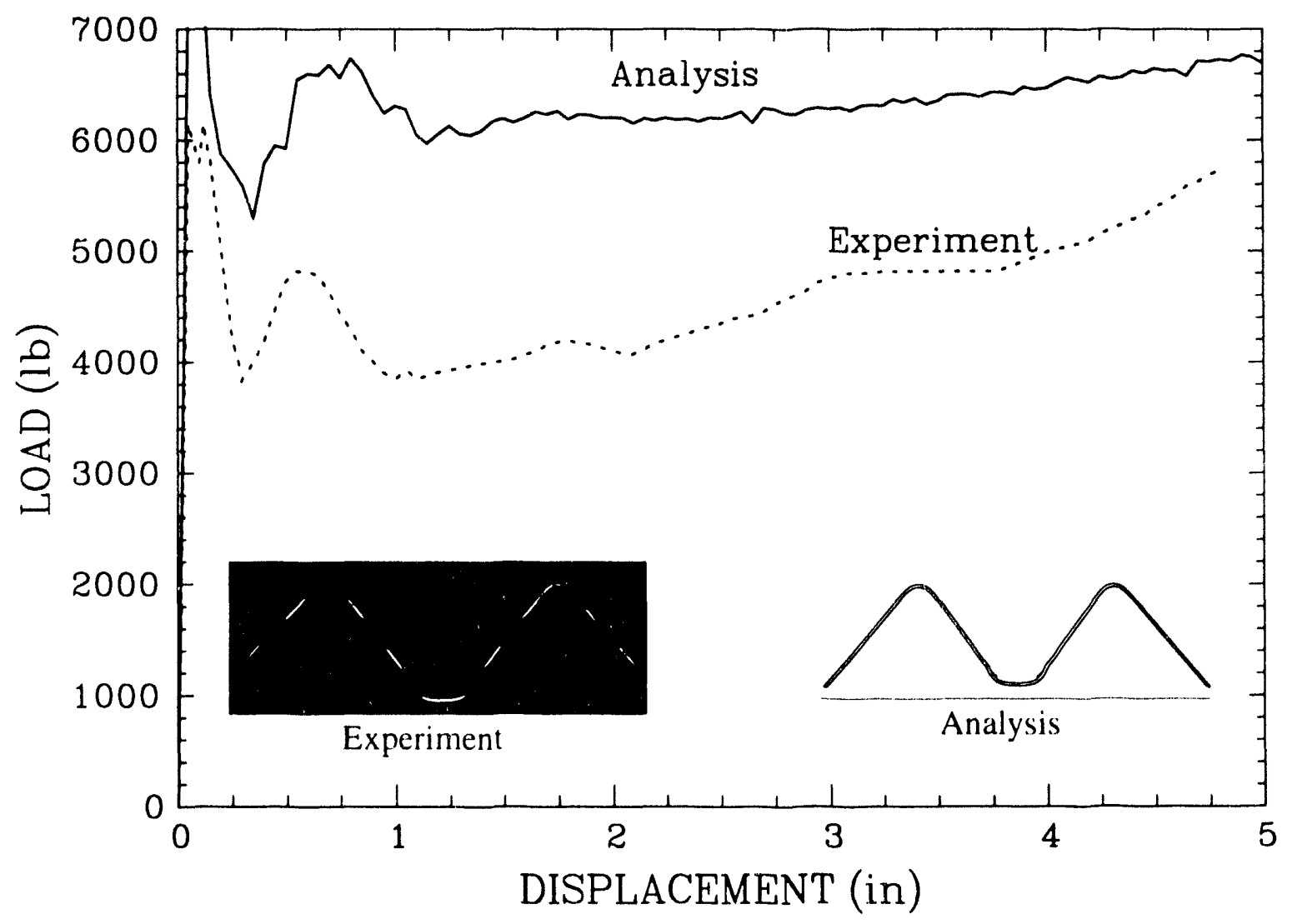

Figure 16. Load versus Displacement and Deformed Shapes for the 304 Cone 


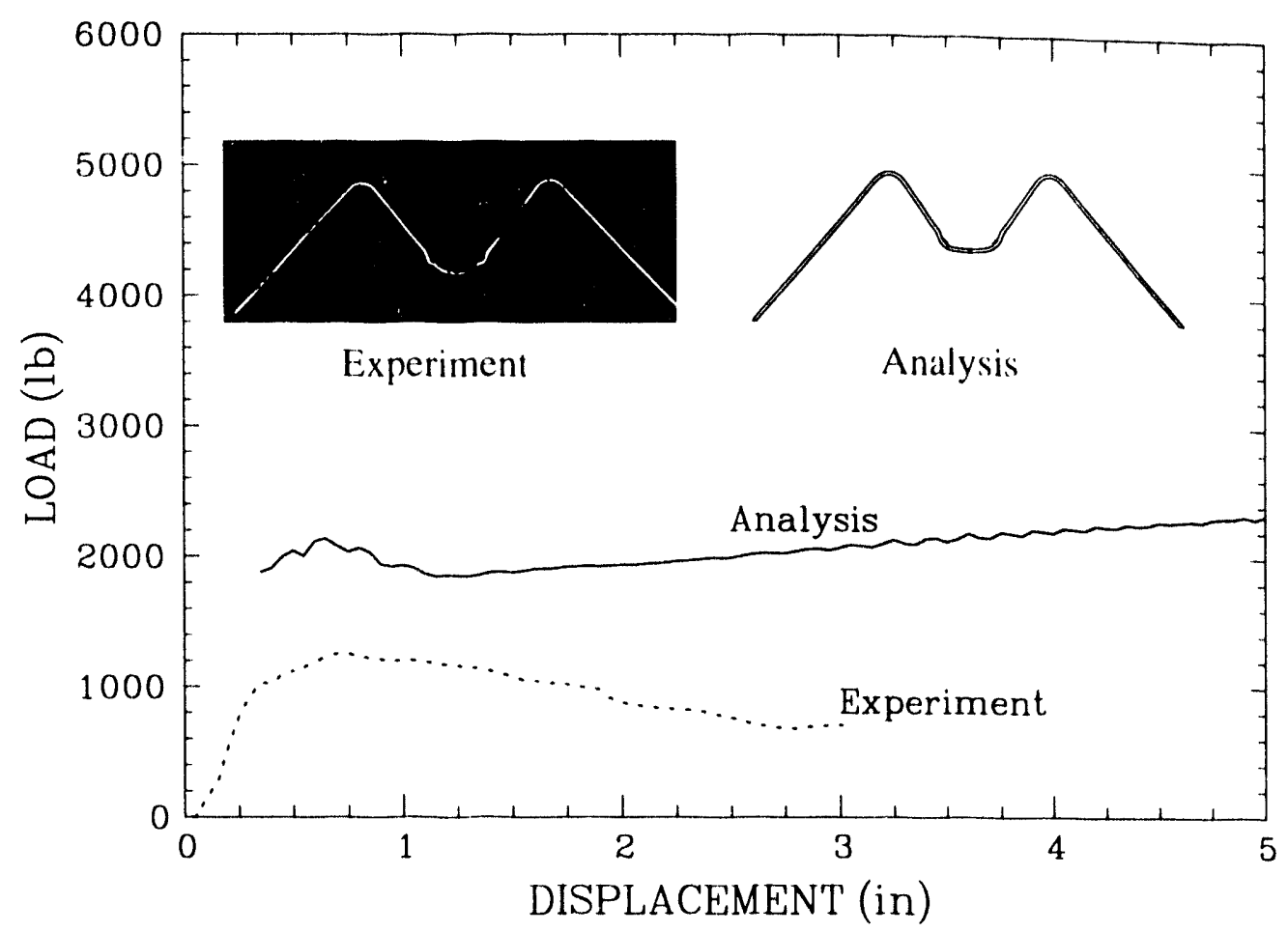

Figure 17. Load versus Displacement and Deformed Shapes for the 6061-T0 Cone

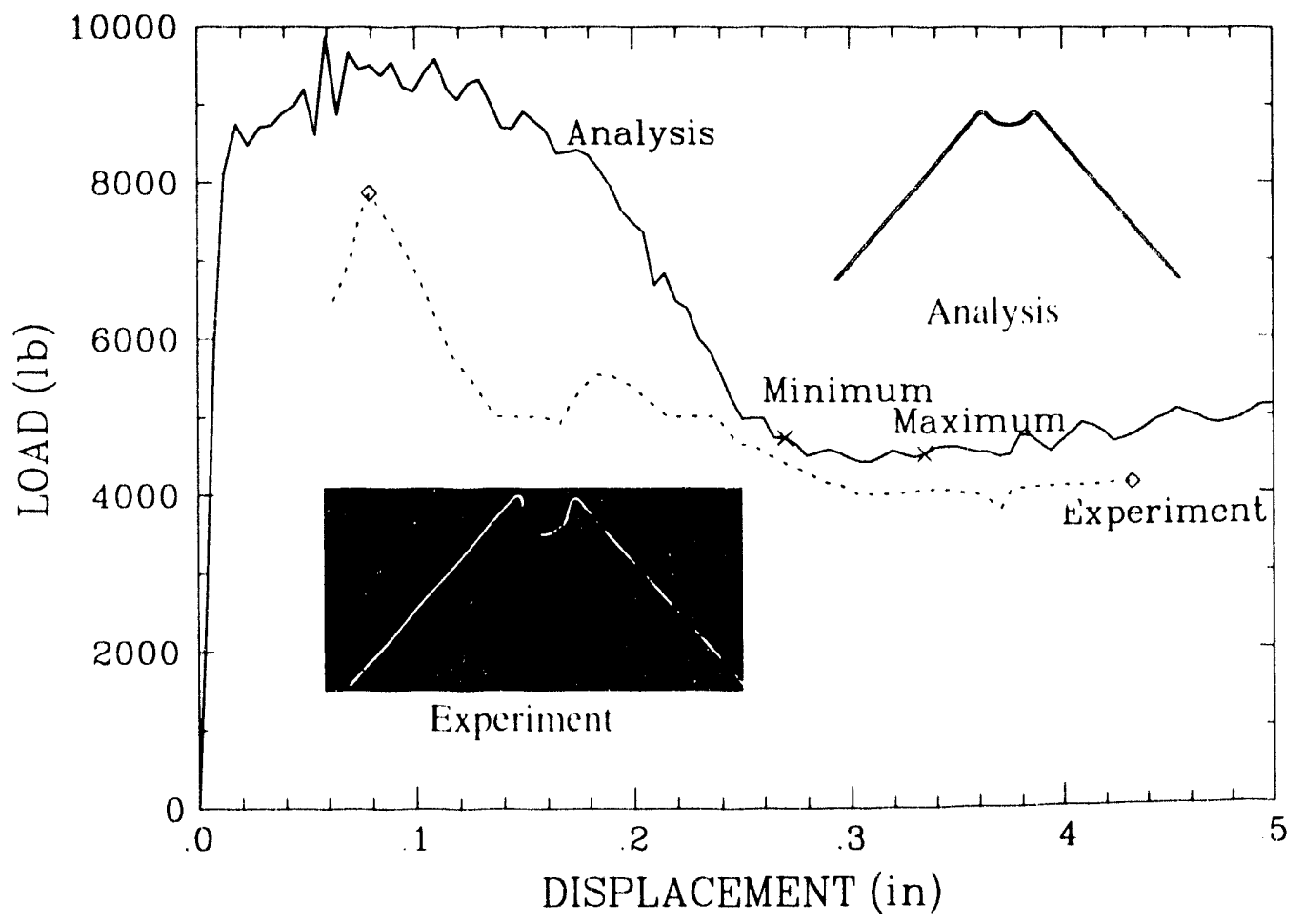

Figure 18. Load versus Displacement and Deformed Shapes for the 6061-T6 Cone 


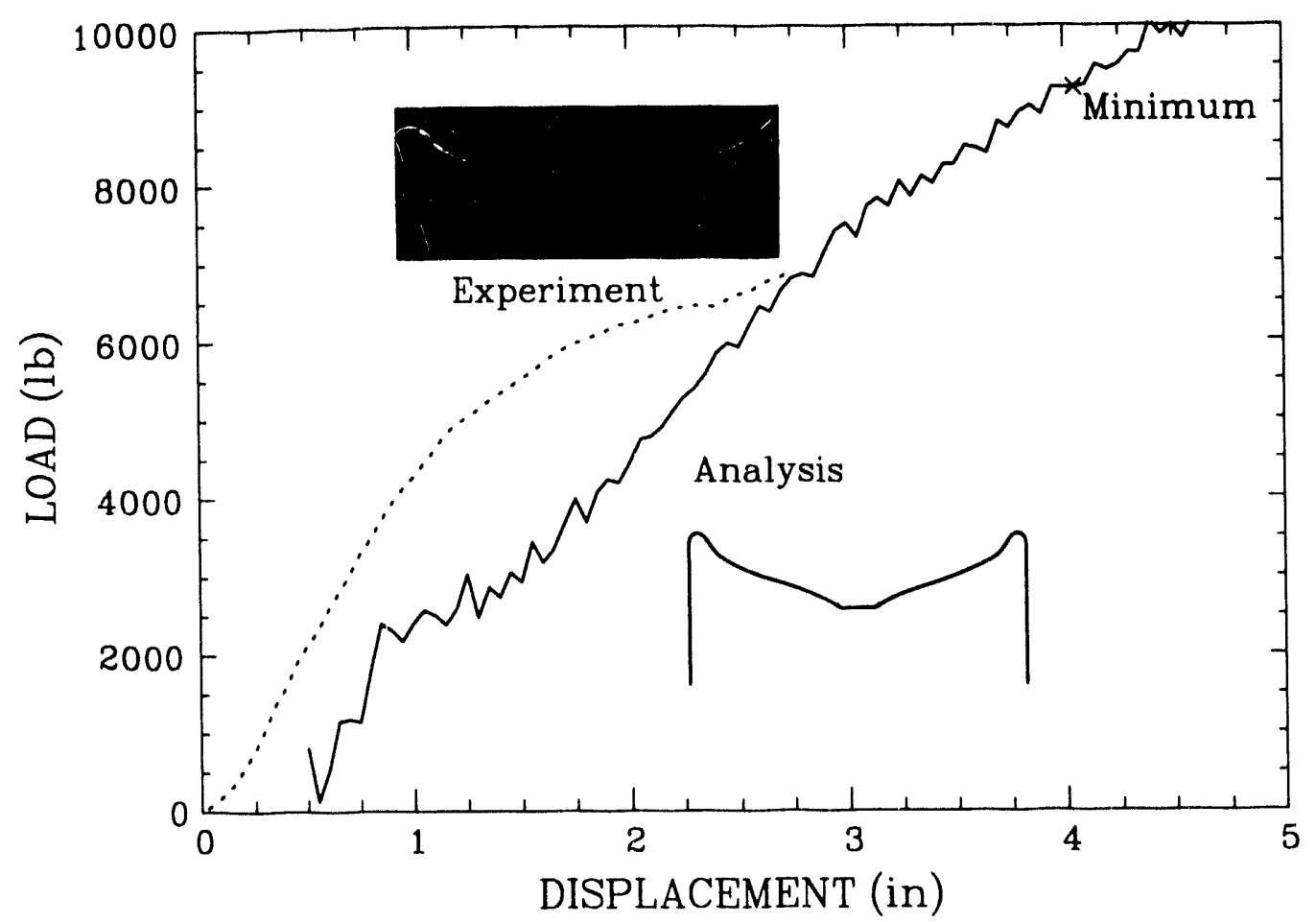

Figure 19. Load versus Displacement and Deformed Shapes for the 304 Cylinder

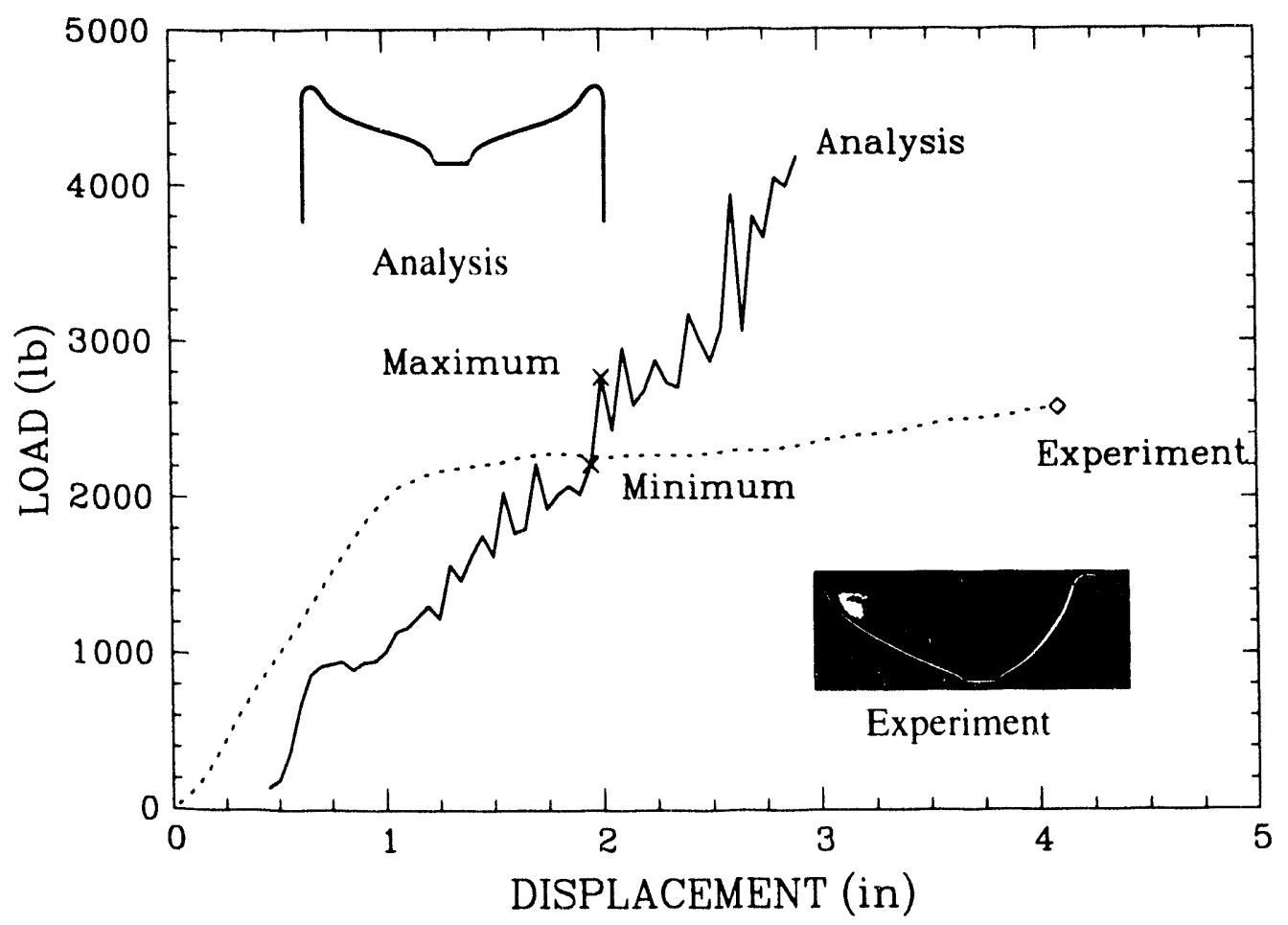

Figure 20. Load versus Displacement and Deformed Shapes for the 6061-T0 Cylinder 


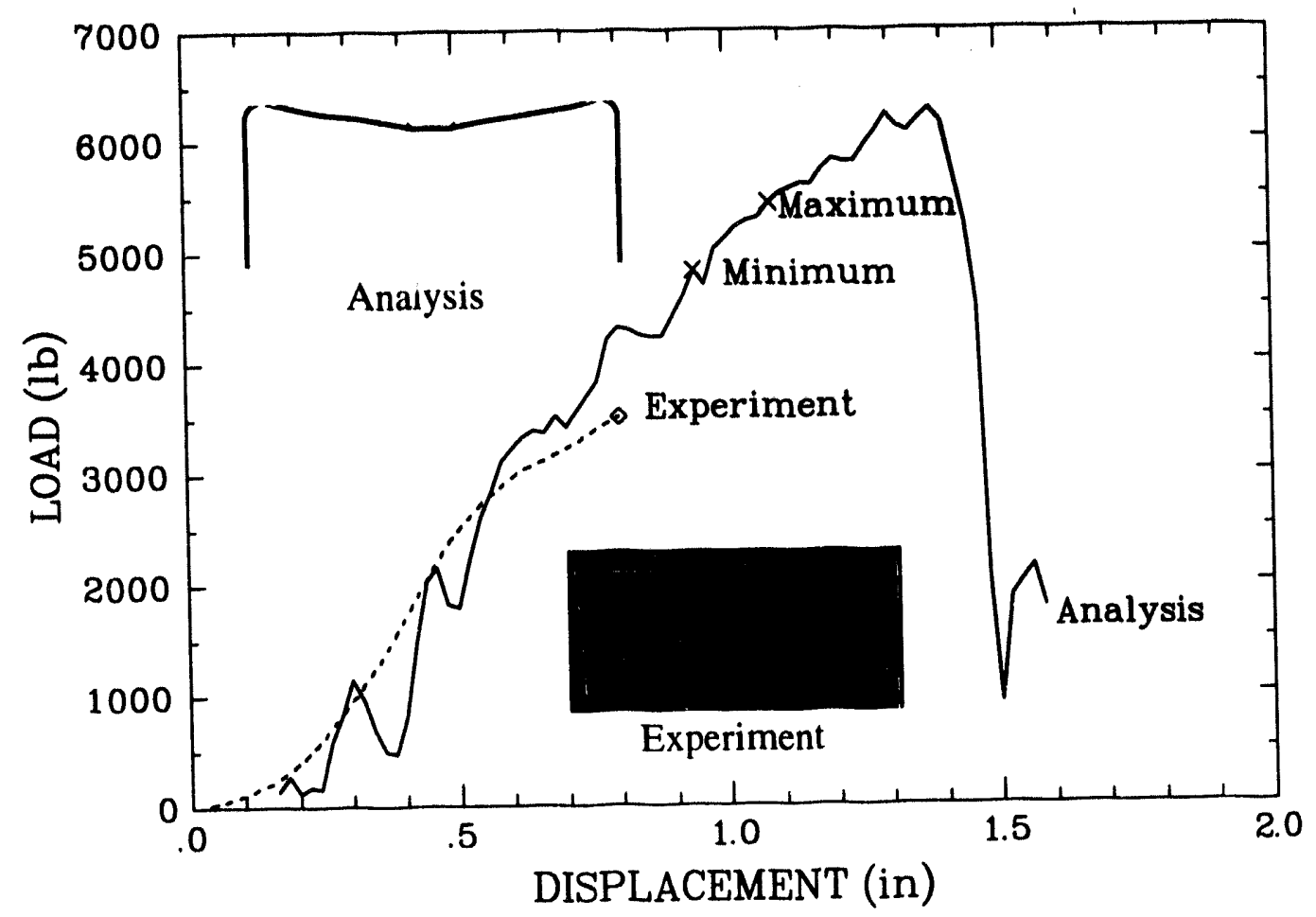

Figure 21. Load versus Displacement and Deformed Shapes for the 6061-T6 Cylinder

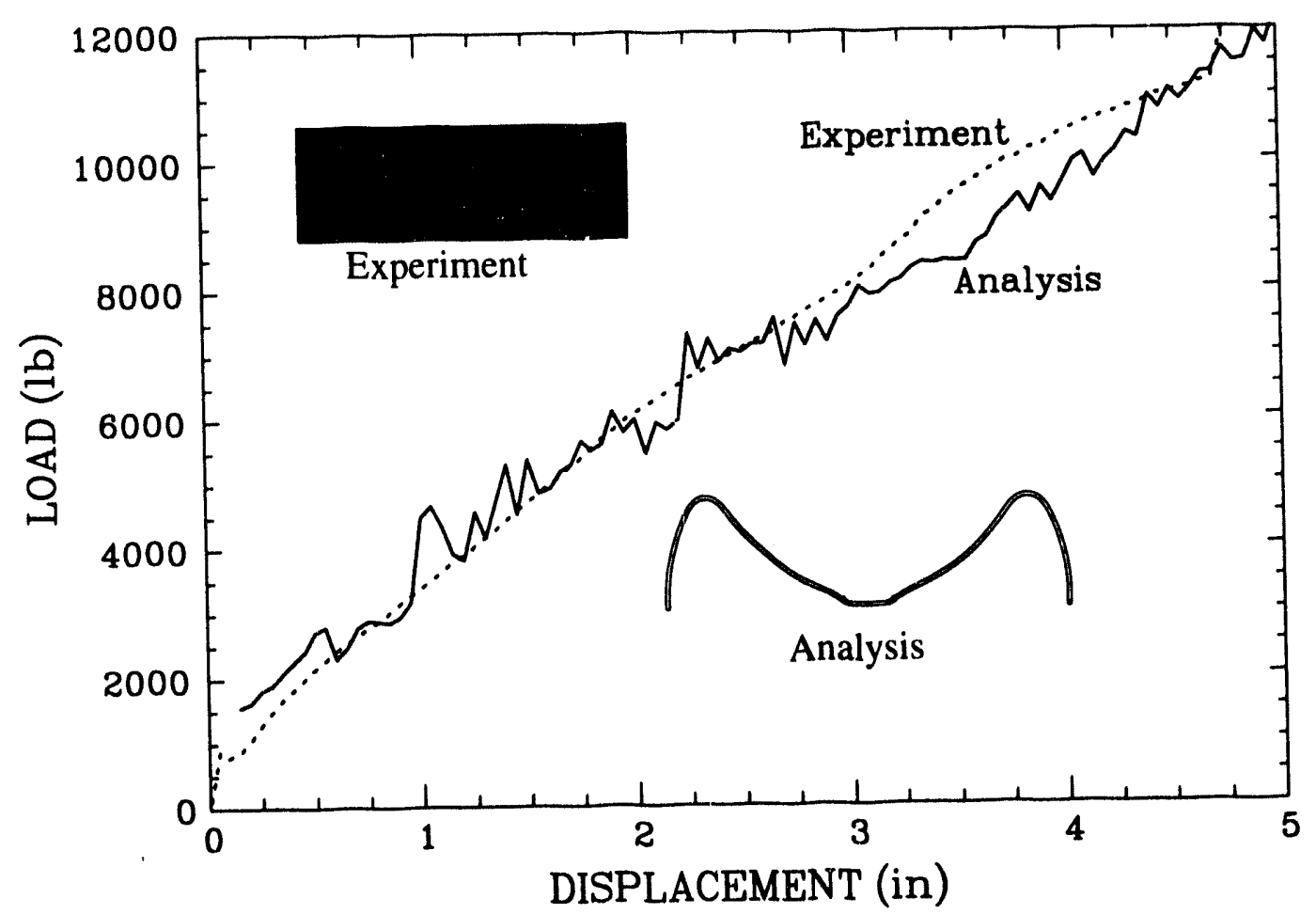

Figure 22. Load versus Displacement and Deformed Shapes for the 304 Hemisphere 


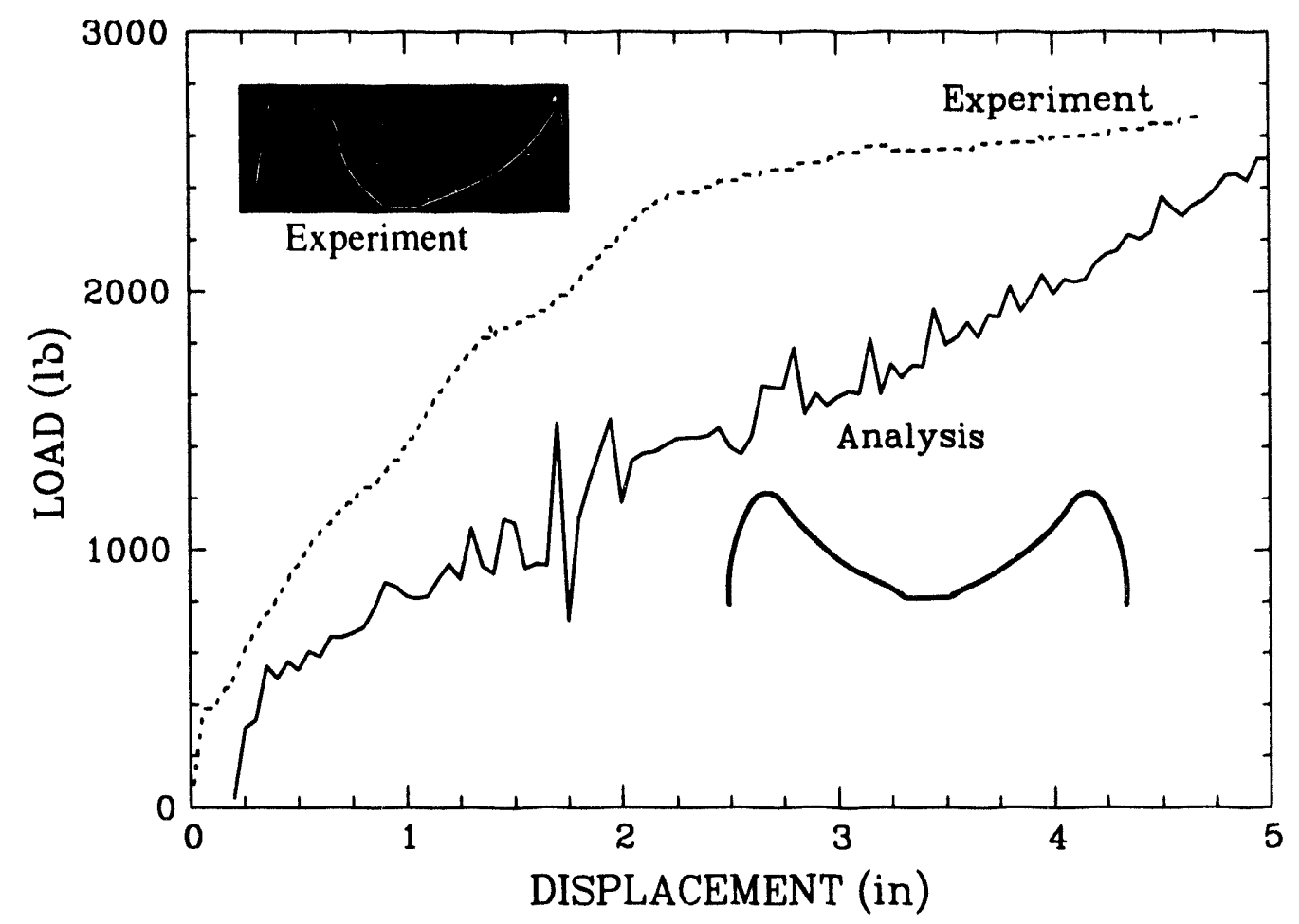

Figure 23. Load versus Displacement and Deformed Shapes for the 6061-T0 Hemisphere

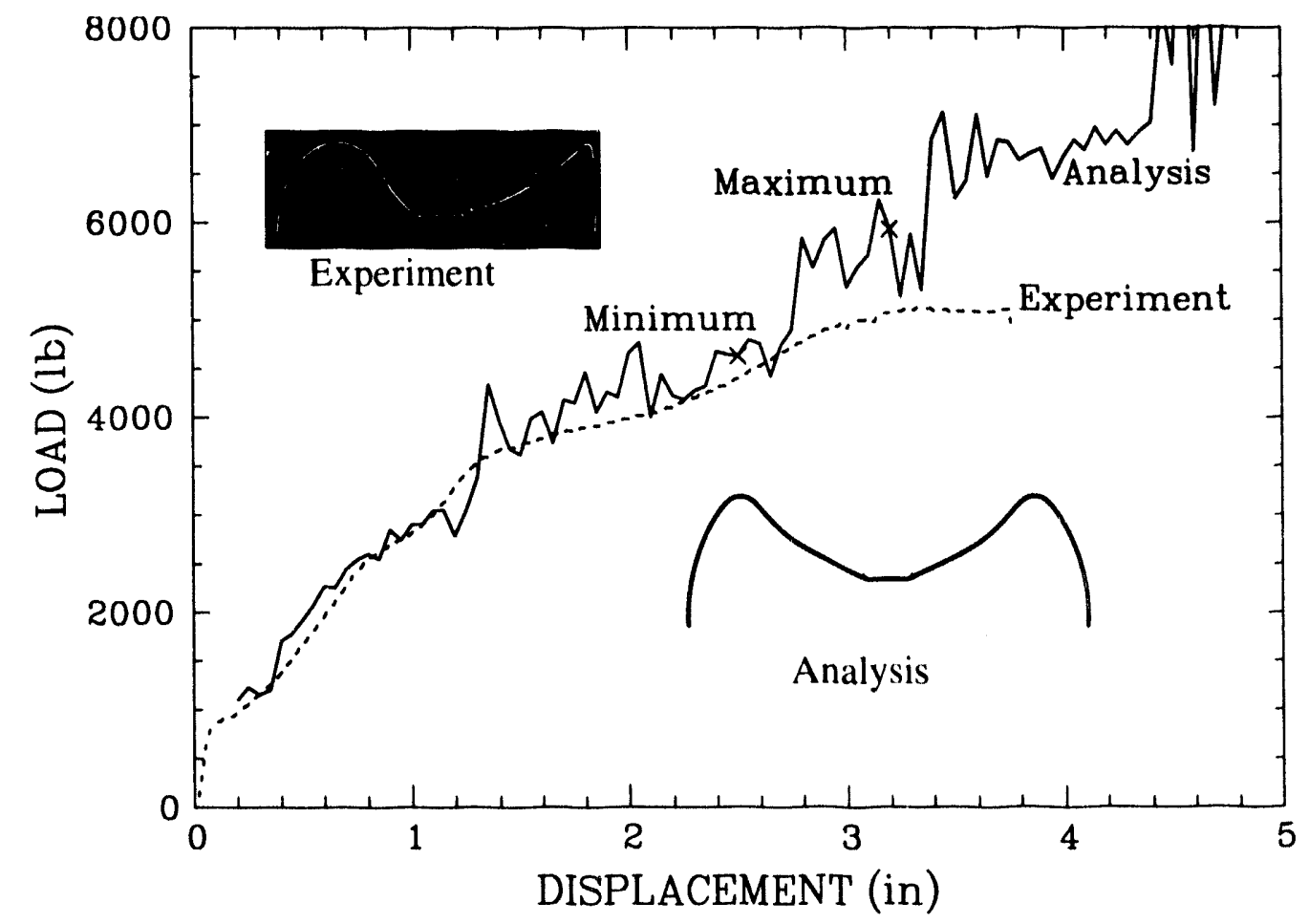

Figure 24. Load versus Displacement and Deformed Shapes for the 6061-T6 Hemisphere 
The computed load versus displacement curve lies above the measured curve for all three truncated cone geometries. The best match in qualitative shape of the load versus displacement curve is seen for the 304 stainless steel (Figure 16). There is some question about the accuracy of the experimental curve for the 6061-T0 aluminum truncated cone test (Figure 17). This test result shows a slow steady load drop (an apparently anomalous behavior). A load increase should result from the rolling hinge extending to a greater diameter on the cone as seen in Figure 16. The load drop should be associated with some other mechanism such as tearing or buckling. However, no such mechanism was identified during this test. The load drop must be considered anomalous until further testing can be accomplished. In the test of the 6061-T6 cone, a ping was heard very early in the test approximately corresponding to the maximum load shown in Figure 18. The post maximum load drop was most likely accompanied by stable tearing around the punch. When the test was arrested, the top of the cone had almost completely torn through.

The circumferential buckling developed in the testing of the cylindrical geometry resulted in a poor match between the analyses and the test results. This buckling phenomenon makes the analysis inherently three-dimensional. A two-dimensional approximation such as that used here will be too stiff. The worst match was for the 6061-T0 aluminum (Figure 20). The best match was for the 6061-T6 aluminum (Figure 21) which tore prior to the develonment of large amounts of circumferential buckling.

The match between measured and computed load versus displacement curves for the hemispheres for all three materials was quite good. This is despite the development of a threelohed circumferential buckling pattern. However, unlike the behavior of the cylinders, the huckling did not appear to contribute to any significant softening until near the end of the machine stroke. It may be that near the end of the stroke, the buckling has moved down the walls of the hemisphere toward where the walls are approaching the geometry of the vertical walls of the cylinder. Therefore, the softening behavior due to circumferential buckling seen in the cylinders is not seen in the hemispheres until quite large deformations are encountered. The experimental deformed shapes shown in Figure 22 through Figure 24 indicate the extent of the buckling. Cutting the hemispheres in half after testing shows the three-lobed buckling mode, an open bend on the left hand side (between the circumferential buckles) along with a tight fold on the right hand side (directly through a buckle).

Only three of the tests exhibited failures, the 6061-T6 aluminum cone, and the 6061-T0 and T6 aluminum cylinders. Failure of the 6061-T6 cone was predicted to occur between 0.27 and 0.34 inches of punch displacement. In the test, tearing probably initiated at about 0.08 inches of punch displacement and the top was almost completely torn through by 0.43 inches of punch displacement. For this initially stiff geometry and relatively low ductility material, minor misalignment along the load train particularly between the punch and top of the cone could be responsible for the discrepancy between the experiment and the analysis.

The 6061-T0 cylinder was predicted to tear at a displacement between 1.95 and 2.0 inches. In the experiment, tearing started at 4.09 inches. The discrepancy here can be explained by the inability of the two-dimensional analysis to model the circumferential buckling. However. the analysis made a much better prediction of the load at which tearing occurred (predicted between 2200 and 2800 pounds, measured at 2600 pounds). Because tearing in the cylinder 
test is driven by necking of the cylinder material around the punch (a load controlled event which can be accurately captured by the two-dimensional analysis) the prediction of load at failure should be more accurate than displacement at failure.

The 6061-T6 cylinder was predicted to tear between 0.94 and 1.08 inches of punch displacement. Tearing was observed at 0.8 inches of punch displacement. The small displacements in this test did not permit the formation of any significant circumferential buckling. Therefore, the prediction of tearing was better than for the 6061-T0 material. The load to failure was predicted to be between 4700 and 5400 pounds. Tearing was observed at 3500 pounds. This load discrepancy is unexplained. However, for both the tests of 6061-T6 in which failure occurred, tearing occurred prior to the predicted value. There is a possibility that the material used to fabricate the test specimens had a lower ductility than the tensile test specimens run earlier[1] which were used to establish the prediction of tearing initiation.

In summary, the two-dimensional model of the hemisphere and the cylinder geometries was too stiff. The structures are exhib:t circumferential buckling which cannot be captured by twodimensional analyses. Three-dimensional analyses of these structures were investigated and found to be prohibitively expensive to carry out using continuum (hex) elements.

Implementation of shells in the three dimensional, quasistatic code, JAC3D, is underway. Use of shell elements for this type of analysis will be investigated when they become available. The circumferential buckling observed in the testing of the cylindrical and hemisfinerical structures implies that the results of Sections 2 through 4, are conservative for these geometries. The greater the ductility and subsequent displacement to failure, the greater the conservatism. For those cases with a small displacement to failure (the results of most interest), the results of Sections 2 through 4 are only mildly conservative. 


\section{Conclusions}

The methodology of combining design of experiments strategies with finite element analysis and testing to develop simplified, predictive capabilities suitable for inclusion in a design guide has been demonstrated. This methodology has been utilized to determine the effects of geometric and materials properties parameters on the resistance of exclusion region barriers to tearing during quasistatic crush and puncture environments. The following conclusions resulted from this study.

- The most important parameters in order of importance were:

1. $\varepsilon_{\mathrm{f}}$, the true strain-to-failure

2. b, the top diameter (top diameter affects the geometry i.e., a small top diameter yields a cone or hemisphere while a large top diameter yields a cylinder)

3. $r_{s t}$, the side-to-top radius

4. $\mathrm{D}_{\mathrm{p}}$, the punch diameter (defines the environment i.e., crush versus puncture)

5. $\sigma_{\mathrm{ys}}$, the initial yield strength.

- Increasing the strain-to-failure is the single most effective means of improving the resistance to tearing failure for the modeled structures. For the puncture environment a large displacement cannot be obtained without a large strain-to-failure. For the crush environment, geometric adjustments can be used to some degree to prevent strain localization and subsequent early failure for materials with low to moderate values of strain-to-failure.

- Regression tree diagrams and predictive equations have been developed for the determination of tearing of exclusion region barriers. These equations and diagrams are suitable for inclusion in a design guide.

- Confirmatory tests have shown that the finite element analyses predict tearing with reasonable accuracy except for the specific case of large punch displacements in the cylindrical geometry. For this case, the specimen exhibits circumferential buckling which significantly reduces its stiffness. The two-dimensional analyses cannot capture this buckling mode. Improved analytical accuracy requires three-dimensional analyses which will be performed when improved code features currently under development are implemented. 


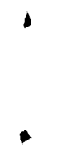

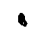

. 


\section{References}

1 Wellman, G. W. and Salzbrenner, R., "Quasistatic Modeling and Testing of Exclusion Region Barrier Mock-Ups", SAND92-0024, Sandia National Laboratories, Albuquerque, New Mexico, March 1992.

2 Peter, John W. M., Statistical Design and Analysis of Experiments, The MacMillan Co., New York, N.Y., 1971.

3 Diegert, K. V., "Analysis of Displacement at Failure", memo to R. Salzbrenner, Sandia National Laboratories, Albuquerque, New Mexico, July 14, 1992.

4 Trinh, K. V. and Gruda, J. D., "Failure Resistance of Thin Shells Against Projectile Penetration", SAND91-8468, ASME 1991 Pressure Vessel and Piping Conference, June 24-27, 1991.

5 Biffle, J. H., "JAC - A Two-Dimensional Finite Element Computer Program for the NonLinear Quasistatic Response of Solids with the Conjugate Gradient Method", SAND810998, Sandia National Laboratories, Albuquerque, New Mexico, April 1984.

6 Stone, C. M., Wellman, G. W., and Krieg, R. D., “A Vectorized Elastic/Plastic Power Law Hardening Material Model Including Luiders Strain”, SAND90-0153, Sandia National Laboratories, Albuquerque, New Mexico, March 1990.

7 Brozzo, P., Deluca, B., and Rendina, R., "A New Method for the Prediction of the Formability Limits of Metal Sheets", Proceedings of the 7th Biennial Congress of International Deep Drawing Research Group, 1972

8 Stone, C. M., and Wellman, G. W., "Implementation of Ductile Failure in PRONTO2D and PRONTO3D", memo to Distribution, Sandia National Laboratories, Albuquerque, New Mexico, April 8,1993.

9 Heinstein, M. W., Attaway, S. W., Swegle, J. W., and Mello, F. J., "A General-Purpose Contact Detection Algorithm for Nonlinear Structural Analysis Codes”, SAND92-2141, Sandia National Laboratories, Albuquerque, New Mexico, May 1993.

10 Diegert, K., “Analysis of Results of 97 Computer Runs”, memo to G. Wellman, Sandia National Laboratories, Albuquerque, New Mexico, December 16, 1992.

11 Brieman, Leo, Friedman, Jerome, Olshen, Richard, and Stone, Charles, Classification and Regression Trees, Wadsworth Publishing Co., Belmont, Ca., 1984.

12 Diegert, K., "Model for Predicting Displacement at Failure", memo to R. Salzbrenner and G. Wellman, Sandia National Laboratories, Albuquerque, New Mexico, February $19,1993$. 



\section{Appendix A}

Table A1: Matrix of the 97 Sets of Parameter Combinations

\begin{tabular}{|c|c|c|c|c|c|c|c|c|c|c|}
\hline Run \# & $\begin{array}{l}\text { Side } \\
\text { Thick } \\
\text { (in) }\end{array}$ & $\begin{array}{l}\text { Top - } \\
\text { Side } \\
\text { Thick } \\
\text { (in) }\end{array}$ & $\begin{array}{l}\text { Top } \\
\text { Dia. } \\
\text { (in) }\end{array}$ & $\begin{array}{l}\text { Punch } \\
\text { Dia. } \\
\text { (in) }\end{array}$ & $\begin{array}{l}\text { Side-to- } \\
\text { Bottom } \\
\text { Radius } \\
\text { (in) }\end{array}$ & $\begin{array}{l}\text { Side- } \\
\text { to-Top } \\
\text { Radius } \\
\text { (in) }\end{array}$ & $\begin{array}{c}\text { Yield } \\
\text { Strength } \\
\text { (ksi) }\end{array}$ & $\begin{array}{l}\text { Hardening } \\
\text { Constant } \\
\text { (ksi) }\end{array}$ & $\begin{array}{l}\text { Hardening } \\
\text { Exponent }\end{array}$ & $\begin{array}{l}\text { Strain- } \\
\text { to- } \\
\text { Failure }\end{array}$ \\
\hline 1 & 0.050 & 0.000 & 1. & 1. & 0.063 & 0.063 & 103 & 83 & 0.26 & 0.3 .3 \\
\hline 2 & 0.050 & 0.000 & 1. & 1. & 0.063 & 0.063 & 103 & 257 & 0.69 & 1.27 \\
\hline 3 & 0.050 & 0.000 & 1. & 1. & 0.500 & 4.000 & 103 & 83 & 0.26 & 1.27 \\
\hline 4 & 0.050 & 0.000 & 1. & 1. & 0.500 & 4.000 & 103 & 257 & 0.69 & 0.33 \\
\hline 5 & 0.050 & 0.000 & 1. & 10 & 0.063 & 4.000 & 37 & 83 & 0.69 & 0.33 \\
\hline 6 & 0.050 & 0.000 & 1. & 10. & 0.063 & $4.0(x)$ & 37 & 257 & 0.26 & 1.27 \\
\hline 7 & 0.050 & 0.000 & 1. & 10 & 0.500 & 0.063 & 37 & 83 & 0.69 & 1.27 \\
\hline 8 & 0.050 & $0.0(X)$ & 1. & 10. & 0.500 & 0.063 & 37 & 257 & 0.26 & 0.33 \\
\hline 9 & 0.050 & 0.000 & 10. & 1. & 0.063 & 0.500 & 103 & 83 & 0.26 & 0.3 .3 \\
\hline 10 & 0.050 & $0.00(0)$ & 10. & 1. & 0.06 .3 & 0.50() & 103 & 257 & 0.69 & 1.27 \\
\hline 11 & 0.050 & 0.000 & 10. & 1. & $0.500)$ & 0.063 & 103 & 83 & 0.26 & 1.27 \\
\hline 12 & 0.050 & 0.000 & 10. & 1. & 0.500 & 0.063 & 103 & 257 & 0.69 & 0.3 .3 \\
\hline 13 & 0.050 & 0.000 & 10 & 10 & 0.063 & 0.06 .3 & 37 & 83 & 0.69 & 0.33 \\
\hline 14 & 0.050 & 0.000 & 10 & 10. & 0.063 & 0.063 & 37 & 257 & 0.26 & 1.27 \\
\hline 15 & 0.050 & 0.000 & 10 & 10. & $0.5(x)$ & 0.500 & 37 & 83 & 0.69 & 1.27 \\
\hline 16 & 0.050 & 0.000 & 10 & 10. & 0.500 & 0.500 & 37 & 257 & 0.26 & 0.33 \\
\hline 17 & 0.050 & 0.200 & 1. & 1. & 0.06 .3 & $4.00(0)$ & .37 & 83 & 0.26 & 0.33 \\
\hline 18 & 0.050 & 0.200 & 1. & 1. & 0.063 & $4.000)$ & 37 & 257 & 0.69 & 1.27 \\
\hline 19 & 0.050 & 0.200 & 1. & 1. & 0.500 & 0.063 & 37 & 83 & 0.26 & 1.27 \\
\hline 20 & 0.050 & 0.200 & 1. & 1. & 0.500 & 0.063 & 37 & 257 & 0.69 & 0.33 \\
\hline 21 & 0.050 & 0.200 & 1. & 10. & 0.063 & 0.063 & 103 & 83 & 0.69 & 0.33 \\
\hline 22 & 0.050 & 0.200 & 1. & 10. & 0.063 & 0.063 & 103 & 257 & 0.26 & 1.27 \\
\hline 23 & 0.050 & 0.200 & 1. & 10 & 0.500 & 4.000 & 103 & 83 & 0.69 & 1.27 \\
\hline 24 & 0.050 & 0.200 & 1. & 10. & 0.500 & 4.000 & 103 & 257 & 0.26 & 0.33 \\
\hline 25 & 0.050 & 0.200 & 10. & 1. & 0.063 & 0.063 & 37 & 83 & 0.26 & 0.33 \\
\hline 26 & 0.050 & 0.200 & 10. & 1. & 0.063 & 0.063 & 37 & 257 & 0.69 & 1.27 \\
\hline 27 & 0.050 & 0.200 & 10. & 1. & 0.500 & 0.500 & 37 & 83 & 0.26 & 1.27 \\
\hline 28 & 0.050 & 0.200 & 10. & 1. & 0.500 & 0.500 & 37 & 257 & 0.69 & 0.33 \\
\hline
\end{tabular}


Table A1: Matrix of the 97 Sets of Parameter Combinations

\begin{tabular}{|c|c|c|c|c|c|c|c|c|c|c|}
\hline Run \# & $\begin{array}{l}\text { Side } \\
\text { Thick } \\
\text { (in) }\end{array}$ & $\begin{array}{l}\text { Top - } \\
\text { Side } \\
\text { Thick } \\
\text { (in) }\end{array}$ & $\begin{array}{l}\text { Top } \\
\text { Dia. } \\
\text { (in) }\end{array}$ & $\begin{array}{l}\text { Punch } \\
\text { Dia. } \\
\text { (in) }\end{array}$ & $\begin{array}{l}\text { Side-to- } \\
\text { Bottom } \\
\text { Radius } \\
\text { (in) }\end{array}$ & $\begin{array}{l}\text { Side- } \\
\text { to-Top } \\
\text { Radius } \\
\text { (in) }\end{array}$ & $\begin{array}{l}\text { Yield } \\
\text { Strength } \\
\text { (ksi) }\end{array}$ & $\begin{array}{l}\text { Hardening } \\
\text { Constant } \\
\text { (ksi) }\end{array}$ & $\begin{array}{l}\text { Hardening } \\
\text { Exponent }\end{array}$ & $\begin{array}{l}\text { Strain- } \\
\text { to- } \\
\text { Failure }\end{array}$ \\
\hline 29 & 0.050 & 0.200 & 10. & 10. & 0.063 & 0.500 & 103 & 83 & 0.69 & 0.33 \\
\hline 30 & 0.050 & 0.200 & 10. & 10. & 0.063 & 0.500 & 103 & 257 & 0.26 & 1.27 \\
\hline 31 & 0.050 & 0.200 & 10. & 10. & 0.500 & 0.063 & 103 & 83 & 0.69 & 1.27 \\
\hline 32 & 0.050 & 0.200 & 10. & 10. & 0.500 & 0.063 & 103 & 257 & 0.26 & 0.33 \\
\hline 33 & 0.125 & 0.000 & 1. & 1. & 0.063 & 4.000 & 103 & 83 & 0.69 & 1.27 \\
\hline 34 & 0.125 & 0.000 & 1. & 1. & 0.063 & 4.000 & 103 & 257 & 0.26 & 0.33 \\
\hline 35 & 0.125 & 0.000 & 1. & 1. & 0.500 & 0.063 & 103 & 83 & 0.69 & 0.33 \\
\hline 36 & 0.125 & 0.000 & 1. & 1. & 0.500 & 0.063 & 103 & 257 & 0.26 & 1.27 \\
\hline 37 & 0.125 & 0.000 & 1. & 10 & 0.063 & 0.063 & 37 & 83 & 0.26 & 1.27 \\
\hline 38 & 0.125 & 0.000 & 1. & 10 & 0.063 & 0.063 & 37 & 257 & 0.69 & 0.33 \\
\hline 39 & 0.125 & 0.000 & 1. & 10 & 0.500 & 4.000 & 37 & 83 & 0.26 & 0.33 \\
\hline 40 & 0.125 & $0.000)$ & 1. & 10. & 0.500 & $4.0(0)$ & 37 & 257 & 0.69 & 1.27 \\
\hline 41 & 0.125 & $0.00(0)$ & 10 & 1. & 0.063 & 0.063 & 103 & 83 & 0.69 & 1.27 \\
\hline 42 & 0.125 & $0.0(0)$ & 10. & 1. & 0.063 & 0.063 & 103 & 257 & 0.26 & 0.33 \\
\hline 43 & 0.125 & $0.0(0)$ & 10. & 1. & 0.500 & $0.5(x)$ & 103 & 83 & 0.69 & 0.33 \\
\hline 44 & 0.125 & $0.0(0)$ & 10. & 1. & 0.500 & $(0.500)$ & 103 & 257 & 0.26 & 1.27 \\
\hline 4.5 & 0.12 .5 & 0.00() & 10. & 10. & 0.063 & 0.500 & 37 & 83 & 0.26 & 1.27 \\
\hline 46 & 0.125 & $0.0(0)$ & 10. & 10 & 0.06 .3 & $0.5(k)$ & 37 & 257 & 0.69 & 0.33 \\
\hline 47 & 0.125 & $0.00(0)$ & 10 & 10. & 0.5() 0 & 0.063 & 37 & 83 & 0.26 & 0.33 \\
\hline 48 & 0.125 & $0.0(0)$ & 10. & 10 & 0.500 & 0.063 & 37 & 257 & 0.69 & 1.27 \\
\hline 49 & 0.125 & 0.125 & 1. & 1. & 0.063 & 0.063 & 37 & 83 & 0.69 & 1.27 \\
\hline 50 & 0.125 & 0.125 & 1. & 1. & 0.063 & 0.063 & 37 & 257 & 0.26 & 0.33 \\
\hline 51 & 0.125 & 0.125 & 1. & 1. & 0.500 & $4.0(0)$ & 37 & 83 & 0.69 & 0.3 .3 \\
\hline 52 & 0.125 & 0.125 & 1. & 1. & 0.500 & $4 .(0)(X)$ & 37 & 257 & 0.26 & 1.27 \\
\hline 53 & 0.125 & 0.125 & 1. & 10. & 0.063 & $4.00(0)$ & 103 & 83 & 0.26 & 1.27 \\
\hline 54 & 0.125 & 0.125 & 1. & 10. & 0.063 & 4.000 & 103 & 257 & 0.69 & 0.33 \\
\hline 55 & 0.125 & 0. 125 & 1. & 10. & 0.500 & 0.063 & 103 & 83 & 0.26 & 0.33 \\
\hline 56 & 0.125 & 0.125 & 1. & 10. & 0.500 & 0.063 & 103 & 257 & 0.69 & 1.27 \\
\hline 57 & 0.125 & 0.125 & 10. & 1. & 0.063 & 0.500 & 37 & 83 & 0.69 & 1.27 \\
\hline 58 & 0.125 & 0.125 & 10. & 1. & 0.063 & $0.5(x)$ & 37 & 257 & 0.26 & 0.33 \\
\hline
\end{tabular}


Table A1: Matrix of the 97 Sets of Parameter Combinations

\begin{tabular}{|c|c|c|c|c|c|c|c|c|c|c|}
\hline Run \# & $\begin{array}{l}\text { Side } \\
\text { Thick } \\
\text { (in) }\end{array}$ & $\begin{array}{l}\text { Top - } \\
\text { Side } \\
\text { Thick } \\
\text { (in) }\end{array}$ & $\begin{array}{l}\text { Top } \\
\text { Dia. } \\
\text { (in) }\end{array}$ & $\begin{array}{l}\text { Punch } \\
\text { Dia. } \\
\text { (in) }\end{array}$ & $\begin{array}{c}\text { Side-to- } \\
\text { Bottom } \\
\text { Radius } \\
\text { (in) }\end{array}$ & $\begin{array}{l}\text { Side- } \\
\text { to-Top } \\
\text { Radius } \\
\text { (in) }\end{array}$ & $\begin{array}{l}\text { Yield } \\
\text { Strength } \\
\text { (ksi) }\end{array}$ & $\begin{array}{l}\text { Hardening } \\
\text { Constant } \\
\text { (ksi) }\end{array}$ & $\begin{array}{c}\text { Hardening } \\
\text { Exponent }\end{array}$ & $\begin{array}{c}\text { Strain- } \\
\text { to- } \\
\text { Failure }\end{array}$ \\
\hline 59 & 0.125 & 0.125 & 10. & 1. & 0.500 & 0.063 & 37 & 83 & 0.69 & 0.33 \\
\hline 60 & 0.125 & 0.125 & 10. & 1. & 0.500 & 0.063 & 37 & 257 & 0.26 & 1.27 \\
\hline 61 & 0.125 & 0.125 & 10. & 10 & 0.063 & 0.063 & 103 & 83 & 0.26 & 1.27 \\
\hline 62 & 0.125 & 0.125 & 10. & 10. & 0.063 & 0.063 & 103 & 257 & 0.69 & 0.33 \\
\hline 63 & 0.125 & 0.125 & 10. & 10. & 0.500 & 0.500 & 103 & 83 & 0.26 & 0.33 \\
\hline 64 & 0.125 & 0.125 & 10. & 10. & 0.500 & 0.500 & 103 & 257 & 0.69 & 1.27 \\
\hline 65 & 0.081 & 0.081 & 6. & 5. & 0.250 & 0.250 & 70 & 170 & 0.48 & 0.80 \\
\hline 66 & 0.081 & 0.081 & 6. & 5. & 0.250 & 0.250 & 20 & 170 & 0.48 & 0.80 \\
\hline 67 & 0.081 & 0.081 & 6. & 5. & 0.250 & 0.250 & 120 & 170 & 0.48 & 0.80 \\
\hline 68 & 0.081 & 0.081 & 6. & 5. & 0.250 & 0.250 & 70 & 40 & 0.48 & 0.80 \\
\hline 69 & 0.081 & 0.081 & 6. & 5. & 0.250 & 0.250 & 70 & $3(x)$ & 0.48 & 0.80 \\
\hline 70 & 0.081 & 0.081 & 6. & 5. & 0.250 & 0.250 & 70 & 170 & 0.15 & 0.80 \\
\hline 71 & 0.081 & 0.081 & 6. & 5. & 0.250 & 0.250 & 70 & 170 & 0.80 & 0.80 \\
\hline 72 & 0.081 & 0.081 & 6. & 5. & 0.250 & 0.250 & 70 & 170 & 0.48 & 0.10 \\
\hline 73 & 0.081 & 0.081 & 6. & 5. & 0.250 & 0.250 & 70 & 170 & 0.48 & 1.50 \\
\hline 74 & 0.060 & 0.000 & 1. & 1. & 0.063 & 0.500 & 37 & 170 & 0.48 & 0.33 \\
\hline 75 & 0.060 & 0.000 & 1. & 1. & 0.063 & $0.500)$ & 37 & 170 & 0.48 & 0.80 \\
\hline 76 & 0.060 & 0.000 & 1. & 1. & 0.063 & 0.500 & 80 & 170 & 0.48 & 0.33 \\
\hline 77 & 0.060 & 0.000 & 1. & 1. & 0.063 & 0.500 & 80 & 170 & 0.48 & 0.80 \\
\hline 78 & 0.060 & 0.000 & 6. & 1. & 0.063 & 0.500 & 60 & 170 & 0.48 & 0.20 \\
\hline 79 & 0.060 & 0.000 & 6. & 1. & 0.063 & 0.500 & 60) & 170 & 0.48 & 0.50 \\
\hline 80 & 0.060 & 0.000 & 6. & 1. & 0.063 & 2.000 & 60 & 170 & 0.48 & 0.20 \\
\hline 81 & 0.060 & 0.000 & 6. & 1. & 0.063 & 2.000 & 60 & 170 & 0.48 & 0.50 \\
\hline 82 & 0.060 & 0.000 & 1. & 1. & 0.063 & 0.500 & 60 & 170 & 0.48 & 0.50 \\
\hline 83 & 0.060 & 0.000 & 1. & 1. & 0.063 & $2.000)$ & 60 & 170 & 0.48 & 0.50 \\
\hline 84 & 0.060 & 0.000 & 1. & 1. & 0.063 & 0.500 & 60 & 170 & 0.48 & 0.20 \\
\hline 85 & 0.060 & 0.000 & 1. & 1. & 0.063 & 2.000 & 60 & 170 & 0.48 & 0.20 \\
\hline 86 & 0.060 & $0.00(0)$ & 1. & 10. & 0.063 & $0.5(0)$ & 37 & 170 & 0.48 & 0.33 \\
\hline 87 & 0.060 & $0.00(0)$ & 1. & 10. & 0.063 & $0.5(x)$ & 37 & 170 & 0. 48 & 0.80 \\
\hline 88 & 0.060 & 0.000 & 1. & 10 & 0.063 & $0.5(x)$ & 80 & 170 & 0.48 & 0.33 \\
\hline
\end{tabular}


Table A 1: Matrix of the 97 Sets of Parameter Combinations

\begin{tabular}{|c|c|c|c|c|c|c|c|c|c|c|}
\hline Run \# & $\begin{array}{c}\text { Side } \\
\text { Thick } \\
\text { (in) }\end{array}$ & $\begin{array}{l}\text { Top - } \\
\text { Side } \\
\text { Thick } \\
\text { (in) }\end{array}$ & $\begin{array}{l}\text { Top } \\
\text { Dia. } \\
\text { (in) }\end{array}$ & $\begin{array}{l}\text { Punch } \\
\text { Dia. } \\
\text { (in) }\end{array}$ & $\begin{array}{c}\text { Side-to- } \\
\text { Bottom } \\
\text { Radius } \\
\text { (in) }\end{array}$ & $\begin{array}{l}\text { Side- } \\
\text { to-Top } \\
\text { Radius } \\
\text { (in) }\end{array}$ & $\begin{array}{l}\text { Yield } \\
\text { Strength } \\
\text { (ksi) }\end{array}$ & $\begin{array}{l}\text { Hardening } \\
\text { Constant } \\
\text { (ksi) }\end{array}$ & $\begin{array}{l}\text { Hardening } \\
\text { Exponent }\end{array}$ & $\begin{array}{l}\text { Strain- } \\
\text { to- } \\
\text { Failure }\end{array}$ \\
\hline 89 & 0.060 & $0.0(0)$ & 1. & 10. & 0.063 & 0.500 & 80 & 170 & 0.48 & 0.80 \\
\hline 90 & 0.060 & $0.00(0)$ & 6. & 10. & 0.063 & 0.500 & 60 & 170 & 0.48 & 0.20 \\
\hline 91 & $(0.060$ & $0.00(0)$ & 6. & 10. & 0.063 & 0.500 & 60 & 170 & 0.48 & 0.50 \\
\hline 92 & 0.060 & $0.0(x)$ & 6. & 10. & 0.063 & 2.000 & 60 & 170 & 0.48 & 0.20 \\
\hline 93 & 0.060 & 0.00() & 6. & 10. & 0.063 & 2.000 & 60 & 170 & 0.48 & 0.50 \\
\hline 94 & 0.060 & $0.0(x)$ & 1. & 10. & 0.063 & 0.500 & 60 & 170 & 0.48 & 0.50 \\
\hline 9.5 & 0.060 & $0.0(x)$ & 1. & 10. & 0.063 & $2.0(0)$ & 60) & 170 & 0.48 & 0.50 \\
\hline 96 & 0.060 & $0.0(0)$ & 1. & 10. & 0.063 & 0.500 & 6) & 170 & 0.48 & 0.20 \\
\hline 97 & 0.060 & $0.0(0)$ & 1. & 10. & 0.063 & $2.0(x)$ & 6) & 170 & 0.48 & 0.20 \\
\hline
\end{tabular}




\section{Appendix B}

Table B1: Punch Displacement at Failure

\begin{tabular}{|r|r|r|r|r|r|r|}
\hline Run \# & \multicolumn{1}{|l|}{$\delta_{\mathrm{c}}$ (in) } & \multicolumn{1}{l|}{$\begin{array}{l}\text { Maximum } \\
\text { Load (lb) }\end{array}$} & & Run \# & \multicolumn{1}{l|}{$\boldsymbol{\delta}_{\mathrm{c}}$ (in) } & \multicolumn{1}{l}{$\begin{array}{l}\text { Maximum } \\
\text { Load (lb) }\end{array}$} \\
\hline \hline 1 & 0.20 & 5600 & & 26 & $>4.50$ & 32400 \\
\hline 2 & $>4.50$ & 9700 & & 27 & $>4.50$ & 25900 \\
\hline 3 & 3.35 & 11400 & & 28 & 2.50 & 24400 \\
\hline 4 & 2.35 & 10000 & & 29 & 0.55 & 63100 \\
\hline 5 & 3.75 & 38700 & & 30 & $>4.50$ & 93400 \\
\hline 6 & $>4.50$ & 107700 & & 31 & $>4.50$ & 28000 \\
\hline 7 & $>4.50$ & 5000 & & 32 & 0.80 & 34200 \\
\hline 8 & 2.15 & 48900 & & 33 & 2.60 & 28000 \\
\hline 9 & 0.90 & 7800 & & 34 & 1.55 & 40200 \\
\hline 10 & 2.70 & 18600 & & 35 & 0.15 & 32400 \\
\hline 11 & 1.15 & 9200 & & 36 & $>4.50$ & 61200 \\
\hline 12 & 0.95 & 8700 & & 37 & $>4.50$ & 100800 \\
\hline 13 & 0.35 & 25900 & & 38 & 0.50 & 33500 \\
\hline 14 & 1.15 & 64800 & & 39 & 2.60 & 99400 \\
\hline 15 & $>4.50$ & 16000 & & 40 & $>4.50$ & 75100 \\
\hline 16 & 1.25 & 38000 & & 41 & 1.15 & 23700 \\
\hline 17 & 0.60 & 18300 & & 42 & 0.95 & 35100 \\
\hline 18 & $>4.50$ & 23400 & & 43 & 0.75 & 17000 \\
\hline 19 & $>4.50$ & 9000 & & 44 & 1.50 & 48700 \\
\hline 20 & 0.20 & 8400 & & 45 & $>4.50$ & 135800 \\
\hline 21 & 0.20 & 11400 & & 46 & 0.90 & 97600 \\
\hline 22 & $>4.50$ & 137100 & & 47 & 0.20 & 81100 \\
\hline 23 & $>4.50$ & 43200 & & 48 & $>4.50$ & 103600 \\
\hline 24 & 0.65 & 75800 & & 49 & $>4.50$ & 16200 \\
\hline
\end{tabular}


Table B1: Punch Displacement at Failure

\begin{tabular}{|r|r|r|r|r|r|r|}
\hline Run \# & \multicolumn{1}{|c|}{$\delta_{\mathrm{c}}$ (in) } & \multicolumn{1}{c|}{$\begin{array}{l}\text { Maximum } \\
\text { Load (lb) }\end{array}$} & & Run \# & \multicolumn{1}{l|}{$\delta_{\mathrm{c}}$ (in) } & \multicolumn{1}{l|}{$\begin{array}{l}\text { Maximum } \\
\text { Load (lb) }\end{array}$} \\
\hline \hline 25 & 0.95 & 23500 & & 50 & 0.30 & 47400 \\
\hline 51 & 0.50 & 12200 & & 76 & 0.40 & 6100 \\
\hline 52 & $>4.50$ & 86400 & & 77 & $>4.50$ & 10800 \\
\hline 53 & $>4.50$ & 234000 & & 78 & 0.70 & 5500 \\
\hline 54 & 2.30 & 260600 & & 79 & 1.45 & 10200 \\
\hline 55 & 0.40 & 54000 & & 80 & 1.00 & 5600 \\
\hline 56 & $>4.50$ & 111100 & & 81 & 2.20 & 10200 \\
\hline 57 & 2.15 & 30100 & & 82 & $>4.50$ & 9200 \\
\hline 58 & 1.05 & 53300 & & 83 & $>4.50$ & 10800 \\
\hline 59 & 0.80 & 15300 & & 84 & 0.20 & 3800 \\
\hline 60 & 1.80 & 82700 & & 85 & 1.20 & 6500 \\
\hline 61 & 1.15 & 312900 & & 86 & 4.50 & 20800 \\
\hline 62 & 0.45 & 262800 & & 87 & $>4.50$ & 20800 \\
\hline 63 & 0.30 & 132900 & & 88 & 4.50 & 31700 \\
\hline 64 & $>4.50$ & 171400 & & 89 & $>4.50$ & 31700 \\
\hline 65 & $>4.50$ & 46100 & & 90 & 1.25 & 59600 \\
\hline 66 & $>4.50$ & 26700 & & 91 & 3.80 & 69900 \\
\hline 67 & $>4.50$ & 65400 & & 92 & 1.45 & 33000 \\
\hline 68 & $>4.50$ & 33700 & & 93 & 2.40 & 73800 \\
\hline 69 & $>4.50$ & 58200 & & 94 & 4.50 & 52200 \\
\hline 70 & $>4.50$ & 72700 & & 95 & 4.50 & 50600 \\
\hline 71 & $>4.50$ & 36800 & & 96 & 4.45 & 28000 \\
\hline 72 & 0.25 & 30400 & & 97 & 4.40 & 37500 \\
\hline 73 & $>4.50$ & 46100 & & & & \\
\hline 74 & 1.15 & 5300 & & & & \\
\hline 75 & $>4.50$ & 7200 & & & & \\
\hline
\end{tabular}




\section{Appendix C}

Table C1: Predicted Displacement to Failure for the Puncture Environment

\begin{tabular}{|c|c|c|c|c|c|c|c|c|}
\hline Run \# & $\varepsilon_{f}$ & $\mathrm{D}_{\mathrm{p}}(\mathrm{in})$ & $b$ (in) & $\mathrm{r}_{\mathrm{st}}$ (in) & $t_{t}-t_{s}$ (in) & $A(p s i)$ & $\delta_{c}(\mathrm{in})$ & $\delta_{p}$ (in) \\
\hline 84 & 0.2 & 1 & 1 & 0.5 & 0. & 170 & 0.20 & 0.47 \\
\hline 85 & 0.2 & 1 & 1 & 2 & 0 & 170 & 1.20 & 0.87 \\
\hline 78 & 0.2 & 1 & 6 & 0.5 & 0 & 170 & 0.70 & 0.87 \\
\hline 80 & 0.2 & 1 & 6 & 2 & 0 & 170 & 1.00 & 1.14 \\
\hline 1 & 0.33 & 1 & 1 & 0.063 & 0 & 83 & 0.20 & 0.22 \\
\hline 35 & 0.33 & 1 & 1 & 0.063 & 0 & 83 & 0.15 & 0.16 \\
\hline 50 & 0.33 & 1 & 1 & 0.063 & 0.13 & 257 & 0.30 & 0.20 \\
\hline 20 & 0.33 & 1 & 1 & 0.063 & 0.2 & 257 & 0.20 & 0.27 \\
\hline 74 & 0.33 & 1 & 1 & 0.5 & 0 & 170 & 1.15 & 0.47 \\
\hline 76 & 0.33 & 1 & 1 & 0.5 & 0 & 170 & 0.40 & 0.47 \\
\hline 4 & 0.33 & 1 & 1 & 4 & 0 & 257 & 2.35 & 2.22 \\
\hline 34 & 0.33 & 1 & 1 & 4 & 0 & 257 & 1.55 & 1.85 \\
\hline 51 & 0.33 & 1 & 1 & 4 & 0.13 & 83 & 0.50 & 0.50 \\
\hline 17 & 0.33 & 1 & 1 & 4 & 0.2 & 83 & 0.60 & 0.67 \\
\hline 12 & 0.33 & 1 & 10 & 0.063 & 0 & 257 & 0.95 & 1.15 \\
\hline 42 & 0.33 & 1 & 10 & 0.063 & 0 & 257 & 0.95 & 0.89 \\
\hline 59 & 0.33 & 1 & 10 & 0.063 & 0.13 & 83 & 0.80 & 0.74 \\
\hline 25 & 0.33 & 1 & 10 & 0.063 & 0.2 & 83 & 0.95 & 0.96 \\
\hline 9 & 0.33 & 1 & 10 & 0.5 & 0 & 83 & 0.90 & 0.87 \\
\hline 43 & 0.33 & 1 & 10 & 0.5 & 0 & 83 & 0.75 & 0.66 \\
\hline 58 & 0.33 & 1 & 10 & 0.5 & 0.13 & 257 & 1.05 & 1.42 \\
\hline 28 & 0.33 & 1 & 10 & 0.5 & 0.2 & 257 & 2.50 & 1.76 \\
\hline 82 & 0.5 & 1 & 1 & 0.5 & 0 & 170 & 4.50 & 4.49 \\
\hline 83 & 0.5 & 1 & 1 & 2 & 0 & 170 & 4.50 & 4.52 \\
\hline 79 & 0.5 & 1 & 6 & 0.5 & 0 & 170 & 1.45 & 1.89 \\
\hline 81 & 0.5 & 1 & 6 & 2. & 0 & 170 & 2.20 & 2.25 \\
\hline 75 & 0.8 & 1 & 1 & 0.5 & 0 & 170 & 4.50 & 4.49 \\
\hline
\end{tabular}


Table C1: Predicted Displacement to Failure for the Puncture Environment

\begin{tabular}{|r|l|r|r|l|l|r|l|l|}
\hline Run \# & $\varepsilon_{i}$ & $D_{p}$ (in) & $b$ (in) & $r_{s t}$ (in) & $t_{t} t_{s}$ (in) & $A(p s i)$ & $\delta_{c}($ in) & $\delta_{p}$ (in) \\
\hline \hline 77 & 0.8 & 1 & 1 & 0.5 & 0 & 170 & 4.50 & 4.49 \\
\hline 2 & 1.27 & 1 & 1 & 0.063 & 0 & 257 & 4.50 & 4.55 \\
\hline 36 & 1.27 & 1 & 1 & 0.063 & 0 & 257 & 4.50 & 4.46 \\
\hline 49 & 1.27 & 1 & 1 & 0.063 & 0.13 & 83 & 4.50 & 4.42 \\
\hline 19 & 1.27 & 1 & 1 & 0.063 & 0.2 & 83 & 4.50 & 4.53 \\
\hline 3 & 1.27 & 1 & 1 & 4 & 0 & 83 & 3.35 & 3.13 \\
\hline 33 & 1.27 & 1 & 1 & 4 & 0 & 83 & 2.60 & 2.57 \\
\hline 52 & 1.27 & 1 & 1 & 4 & 0.13 & 257 & 4.50 & 4.45 \\
\hline 18 & 1.27 & 1 & 1 & 4 & 0.2 & 257 & 4.50 & 4.54 \\
\hline 11 & 1.27 & 1 & 10 & 0.063 & 0 & 83 & 1.15 & 0.78 \\
\hline 41 & 1.27 & 1 & 10 & 0.063 & 0 & 83 & 1.15 & 1.70 \\
\hline 60 & 1.27 & 1 & 10 & 0.063 & 0.13 & 257 & 1.80 & 2.11 \\
\hline 26 & 1.27 & 1 & 10 & 0.063 & 0.2 & 257 & 4.50 & 4.45 \\
\hline 10 & 1.27 & 1 & 10 & 0.5 & 0 & 257 & 2.70 & 1.90 \\
\hline 44 & 1.27 & 1 & 10 & 0.5 & 0 & 257 & 1.50 & 1.62 \\
\hline 57 & 1.27 & 1 & 10 & 0.5 & 0.13 & 83 & 2.15 & 2.98 \\
\hline 27 & 1.27 & 1 & 10 & 0.5 & 0.2 & 83 & 4.50 & 4.44 \\
\hline & & & & & \\
\hline
\end{tabular}


Table C2: Predicted Displacement to Failure for the Crush Environment

\begin{tabular}{|c|c|c|c|c|c|c|c|c|}
\hline Run \# & $\varepsilon_{f}$ & $\mathrm{D}_{\mathrm{p}}$ (in) & b (in) & $r_{s t}$ (in) & $t_{t}-t_{s}$ (in) & A (psi) & $\delta_{c}$ (in) & $\delta_{p}$ (in) \\
\hline 96 & 0.2 & 10 & 1 & 0.5 & 0 & 170 & 4.45 & 4.43 \\
\hline 97 & 0.2 & 10 & 1 & 2 & 0 & 170 & 4.40 & 4.52 \\
\hline 90 & 0.2 & 10 & 6 & 0.5 & 0 & 170 & 1.25 & 0.82 \\
\hline 92 & 0.2 & 10 & 6 & 2 & 0 & 170 & 1.45 & 1.40 \\
\hline 8 & 0.33 & 10 & 1 & 0.063 & 0 & 257 & 2.15 & 1.32 \\
\hline 38 & 0.33 & 10 & 1 & 0.063 & 0 & 257 & 0.50 & 1.32 \\
\hline 55 & 0.33 & 10 & 1 & 0.063 & 0.13 & 83 & 0.40 & 0.69 \\
\hline 21 & 0.33 & 10 & 1 & 0.063 & 0.2 & 83 & 0.20 & 0.14 \\
\hline 86 & 0.33 & 10 & 1 & 0.5 & 0 & 170 & 4.50 & 4.43 \\
\hline 88 & 0.33 & 10 & 1 & 0.5 & 0 & 170 & 4.50 & 4.43 \\
\hline 5 & 0.33 & 10 & 1 & 4 & 0 & 83 & 3.75 & 3.21 \\
\hline 39 & 0.33 & 10 & 1 & 4 & 0 & 83 & 2.60 & 3.21 \\
\hline 54 & 0.33 & 10 & 1 & 4 & 0.13 & 257 & 2.30 & 1.89 \\
\hline 24 & 0.33 & 10 & 1 & 4 & 0.2 & 257 & 0.65 & 0.77 \\
\hline 13 & 0.33 & 10 & 10 & 0.063 & 0 & 83 & 0.35 & 0.26 \\
\hline 47 & 0.33 & 10 & 10 & 0.063 & 0 & 83 & 0.20 & 0.26 \\
\hline 62 & 0.33 & 10 & 10 & 0.063 & 0.13 & 257 & 0.45 & 0.45 \\
\hline 32 & 0.33 & 10 & 10 & 0.063 & 0.2 & 257 & 0.80 & 0.66 \\
\hline 16 & 0.33 & 10 & 10 & 0.5 & 0 & 257 & 1.25 & 1.29 \\
\hline 46 & 0.33 & 10 & 10 & 0.5 & 0 & 257 & 0.90 & 1.29 \\
\hline 63 & 0.33 & 10 & 10 & 0.5 & 0.13 & 83 & 0.30 & 0.33 \\
\hline 29 & 0.33 & 10 & 10 & 0.5 & 0.2 & 83 & 0.55 & 0.62 \\
\hline 94 & 0.5 & 10 & 1 & 0.5 & 0 & 170 & 4.50 & 4.50 \\
\hline 95 & 0.5 & 10 & 1 & 2 & 0 & 170 & 4.50 & 4.40 \\
\hline 91 & 0.5 & 10 & 6 & 0.5 & 0 & 170 & 3.80 & 3.82 \\
\hline 93 & 0.5 & 10 & 6 & 2 & 0 & 170 & 2.40 & 3.27 \\
\hline 87 & 0.8 & 10 & 1 & 0.5 & 0 & 170 & 4.50 & 4.50 \\
\hline 89 & 0.8 & 10 & 1 & 0.5 & 0 & 170 & 4.50 & 4.50 \\
\hline 7 & 1.27 & 10 & 1 & 0.063 & 0 & 83 & 4.50 & 4.57 \\
\hline 37 & 1.27 & 10 & 1 & 0.063 & 0 & 83 & 4.50 & 4.33 \\
\hline
\end{tabular}


Table C2: Predicted Displacement to Failure for the Crush Environment

\begin{tabular}{|r|r|r|r|l|l|r|l|l|}
\hline Run \# & $\varepsilon_{\mathrm{f}}$ & $\mathrm{D}_{\mathrm{p}}$ (in) & $\mathrm{b}$ (in) & $\mathrm{r}_{\mathrm{st}}$ (in) & $\mathrm{t}_{\mathrm{t}} \mathrm{t}_{\mathrm{s}}$ (in) & $\mathrm{A}$ (psi) & $\delta_{\mathrm{c}}$ (in) & $\delta_{\mathrm{p}}$ (in) \\
\hline \hline 56 & 1.27 & 10 & 1 & 0.063 & 0.13 & 257 & 4.50 & 4.54 \\
\hline 22 & 1.27 & 10 & 1 & 0.063 & 0.2 & 257 & 4.50 & 4.48 \\
\hline 6 & 1.27 & 10 & 1 & 4 & 0 & 257 & 4.50 & 4.54 \\
\hline 40 & 1.27 & 10 & 1 & 4 & 0 & 257 & 4.50 & 4.42 \\
\hline 53 & 1.27 & 10 & 1 & 4 & 0.13 & 83 & 4.50 & 4.47 \\
\hline 23 & 1.27 & 10 & 1 & 4 & 0.2 & 83 & 4.50 & 4.52 \\
\hline 14 & 1.27 & 10 & 10 & 0.063 & 0 & 257 & 1.15 & 2.29 \\
\hline 48 & 1.27 & 10 & 10 & 0.063 & 0 & 257 & 4.50 & 4.21 \\
\hline 61 & 1.27 & 10 & 10 & 0.063 & 0.13 & 83 & 1.15 & 1.38 \\
\hline 31 & 1.27 & 10 & 10 & 0.063 & 0.2 & 83 & 4.50 & 4.42 \\
\hline 15 & 1.27 & 10 & 10 & 0.5 & 0 & 83 & 4.50 & 4.53 \\
\hline 45 & 1.27 & 10 & 10 & 0.5 & 0 & 83 & 4.50 & 4.47 \\
\hline 64 & 1.27 & 10 & 10 & 0.5 & 0.13 & 257 & 4.50 & 4.43 \\
\hline 30 & 1.27 & 10 & 10 & 0.5 & 0.2 & 257 & 4.50 & 4.54 \\
\hline
\end{tabular}




\section{Distribution:}

300 R. L. Schwoebel

323 R. G. Easterling

323 K. V. Diegert (5)

324 V. J. Johnson

324 R. D. Pederson

1400 E. H. Barsis

1425 J. H. Biffle

1434 D. R. Martinez

1500 D. J. McCloskey

1501 C. W. Peterson

1502 P. J. Hommert

1503 D. J. McCloskey (actg)

1561 H. S. Morgan

1561 M. K. Neilsen

1561 G. W. Wellman (10)

1562 R. K. Thomas

1700 R. J. Eagan

1800 A. D. Romig

1832 R. Salsbrenner (5)

1832 R. J. Bourcier

2574 M. J. DeSpain

2645 S. F. Kuehn

2900 W. E. Alzheimer

2900 T. J. Young

$5167 \quad$ K. Ortiz

5400 H. J. Saxton

$5800 \quad$ J. L. Wirth

5803 J. P. Abbin

6411 D. D. Carlson

8742 P. E. Nielan

8742 A. McDonald

8742 K. V. Trinh

8743 M. L. Callabresi

8523-2 Central Technical Files

7141 Technical Libıary (5)

7613-2 Document Processing (10) for DOE/OSTI

7151 Technical Publications

9911 J. Polito 

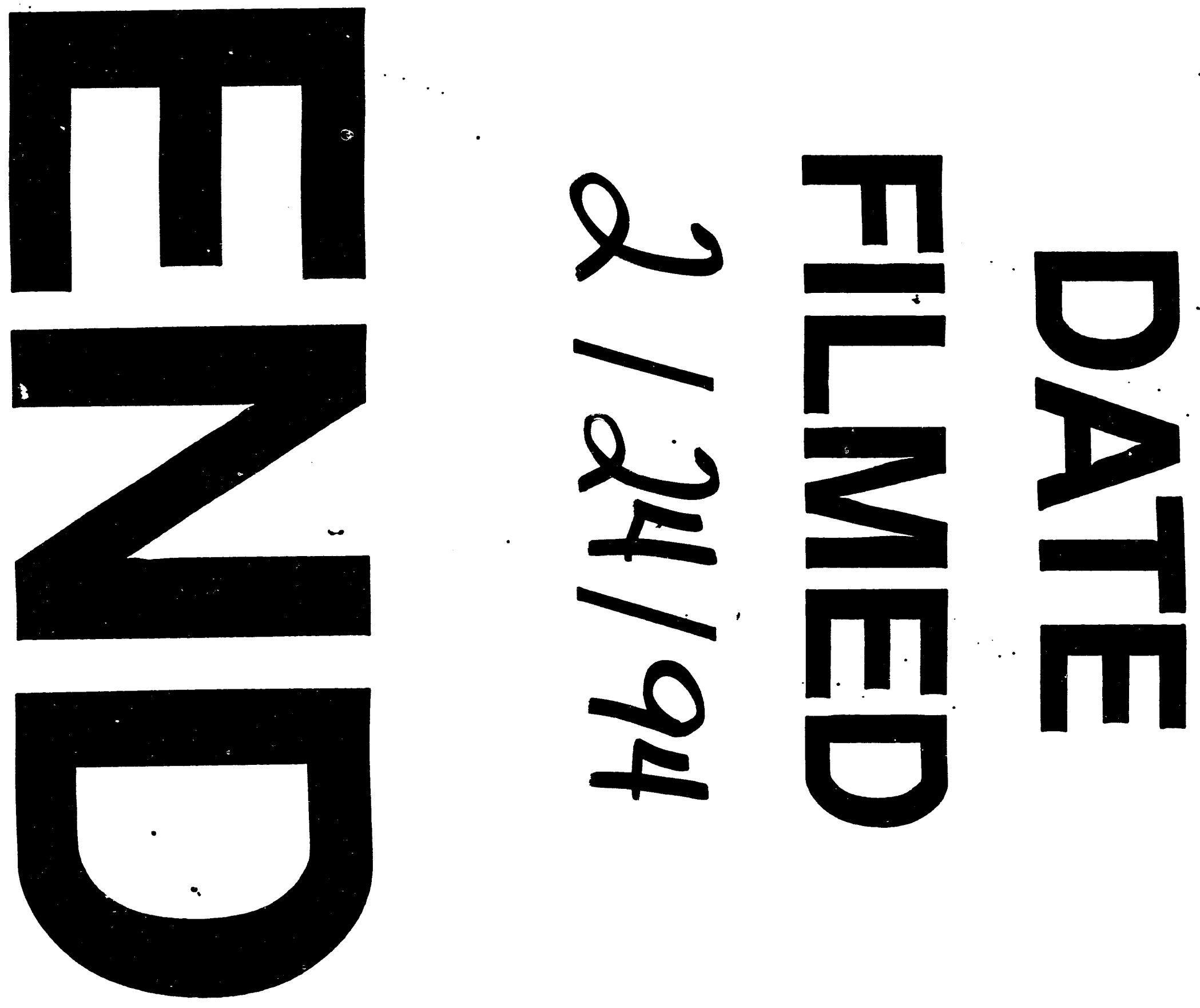
